University of Louisville

ThinkIR: The University of Louisville's Institutional Repository

Electronic Theses and Dissertations

$5-2012$

\title{
Self-regulated practice : a comparison between senior and freshman trumpet students.
}

Jennifer Pope 1988-

University of Louisville

Follow this and additional works at: https://ir.library.louisville.edu/etd

\section{Recommended Citation}

Pope, Jennifer 1988-, "Self-regulated practice : a comparison between senior and freshman trumpet students." (2012). Electronic Theses and Dissertations. Paper 1141.

https://doi.org/10.18297/etd/1141

This Master's Thesis is brought to you for free and open access by ThinkIR: The University of Louisville's Institutional Repository. It has been accepted for inclusion in Electronic Theses and Dissertations by an authorized administrator of ThinkIR: The University of Louisville's Institutional Repository. This title appears here courtesy of the author, who has retained all other copyrights. For more information, please contact thinkir@louisville.edu. 


\title{
SELF-REGULATED PRACTICE: A COMPARISON BETWEEN SENIOR AND FRESHMAN TRUMPET STUDENTS
}

\author{
By \\ Jennifer Pope \\ B.M. in Music Education, University of Kentucky, 2010
}

\begin{abstract}
A Thesis
Submitted to the Faculty of the College of Music of the University of Louisville in Partial Fulfillment of the Requirements

for the Degree of
\end{abstract}

\begin{abstract}
Master of Music in Music Education
\end{abstract}
Department of Music Education

University of Louisville

Louisville, $\mathrm{KY}$

May 2012 
Copyright 2012 by Jennifer Michelle Pope

All rights reserved 


\title{
SELF-REGULATED PRACTICE: A COMPARISON BETWEEN SENIOR AND
} FRESHMAN TRUMPET STUDENTS

\author{
By \\ Jennifer Pope
}

B.M. in Music Education, University of Kentucky, 2010

A Thesis Approved on

April 24, 2012

By the following Thesis Committee:

Robert Amchin, Thesis Director

Amy Acklin

Michael Tunnell 


\section{ACKNOWLEDGEMENTS}

I would like to thank my advising committee for all of their support and advice throughout the process of completing this thesis. Thank you, Dr. Amchin and Dr. Acklin, for your edits and repeated readings of my paper. Thank you, Dr. Tunnell, for allowing your students to contribute to my study, and for being so willing to take part on the committee. I am also grateful to the students who were willing to participate in the study even though it has been a busy semester. I would like to mention my fellow thesiswriting classmates who helped me with the ins and outs of writing a thesis even as they learned the process themselves, and who kept me in the loop anytime they discovered something helpful. And to Phillip, thank you for all the times you offered to make me coffee or to stay up late to keep me company while I type, and for everything else you do. By myself I could not have finished this...so thank you all! 


\section{ABSTRACT \\ SELF-REGULATED PRACTICE: A COMPARISON BETWEEN SENIOR AND FRESHMAN TRUMPET STUDENTS \\ Jennifer Pope}

April 24, 2012

The purpose of this qualitative study was to investigate how four college music students - two seniors and two freshmen-practice as they prepare an étude. Participants were all trumpet players. All participants completed two videotaped sessions of fifteen minutes each. During these sessions, the participants were given one étude to sight-read and rehearse on their own. During the second session, a new étude was provided and the process repeated. These sessions were self-regulated by participants. At the end of each session, participants were given a short survey asking them to describe their methods. The results of the surveys were divided into categories for analysis (grade level and playing experience; and details on techniques used). The videos were analyzed as a supplement in understanding the participants' comments, as well as to discover any additional apparent differences or common themes in pacing and focus between the students. Results showed that each student used different techniques to learn the étude, but the seniors' answers indicated a larger influence of private lessons on their practice routines. Suggestions for future research in the area of practice routines for instrumentalists are offered. 


\section{TABLE OF CONTENTS}

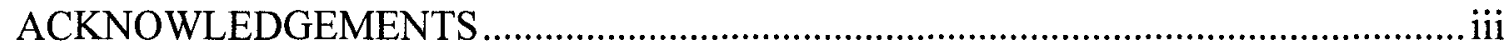

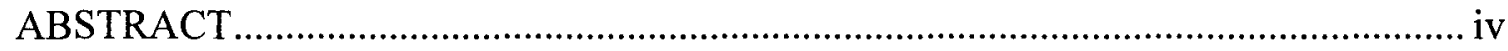

LIST OF FIGURES …......................................................................................... vii

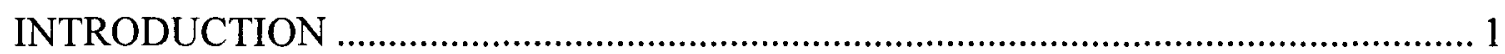

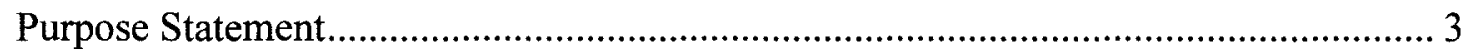

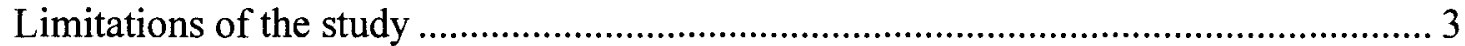

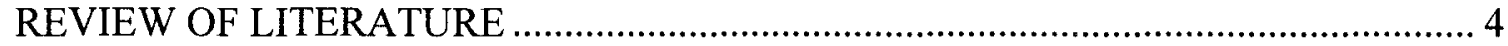

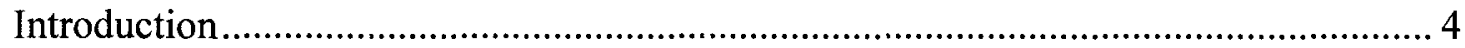

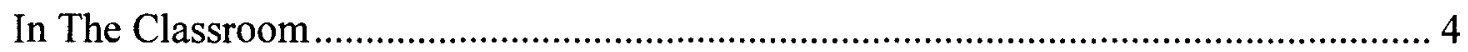

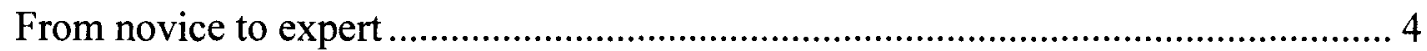

How podium instruction can develop students' musical skills............................... 5

Rehearsal techniques can provide learning tools for students-Structure................. 6

Rehearsal techniques can provide learning tools for students-Modeling................8

Rehearsal techniques can provide learning tools for students-Repetition............. 10

Rehearsal techniques can provide learning tools for students-Kinesthetics .......... 10

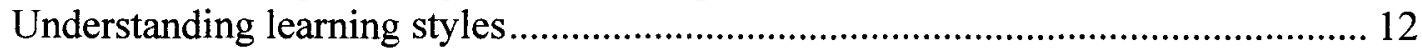

Individual Practice: Innate Talent, Motivation, Time Spent And ............................... 14

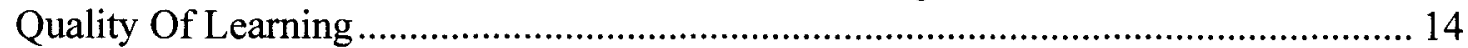

Musical expertise requires more than practice................................................ 14

Motivation to achieve and attitudes regarding practice ..................................... 15

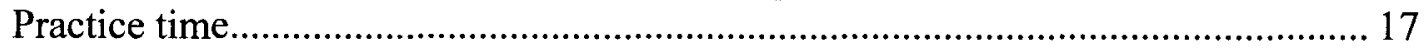

Self-evaluation: accuracy and impact on performance ......................................... 19

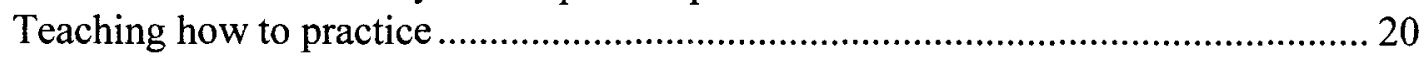

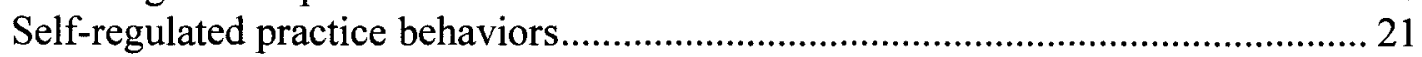

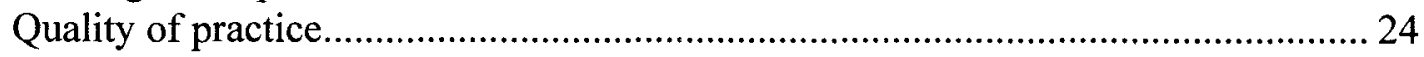

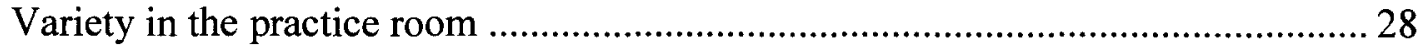

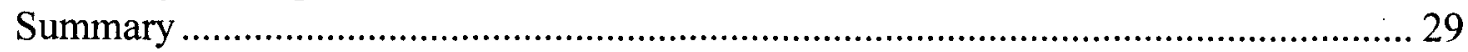

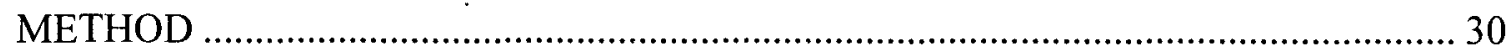

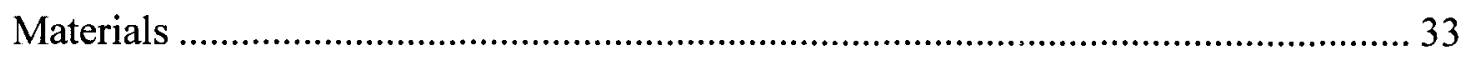

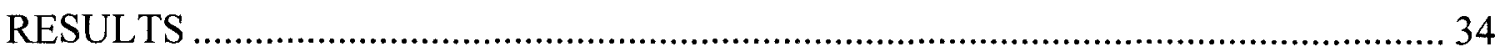

Responses To The Post Practice Survey ......................................................... 42

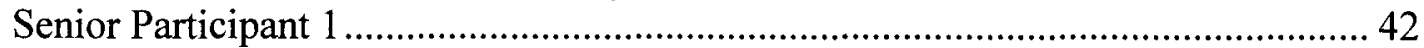

Participant's comments on survey during first session:................................... 42

Participant's comments on survey during second session: ............................... 43

Observations on the practice behaviors of this participant: .............................. 43

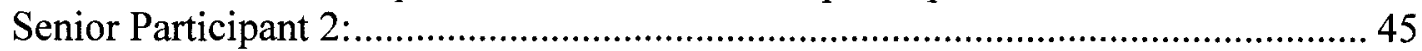


Participant's comments on survey during first session:................................. 45

Participant's comments on survey during second session: ................................ 45

Observations on the practice behaviors of this participant: ............................. 46

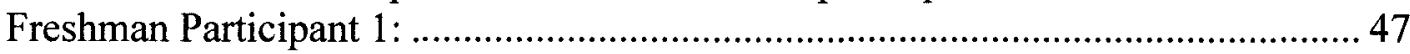

Participant's comments on survey during first session:.................................. 47

Participant's comments on survey during second session: ............................... 47

Observations on the practice behaviors of this participant:............................ 48

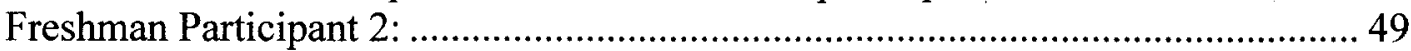

Participant's comments on survey during first session:................................. 49

Participant's comments on survey during second session: ................................ 49

Observations on the practice behaviors of this participant: .............................. 50

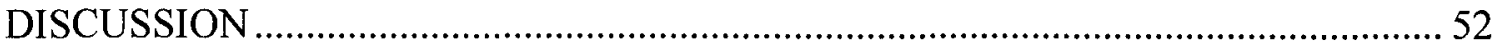

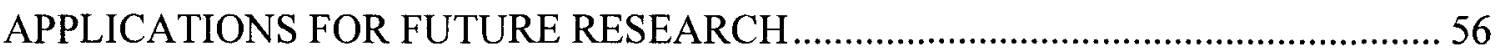

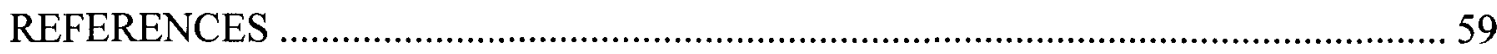

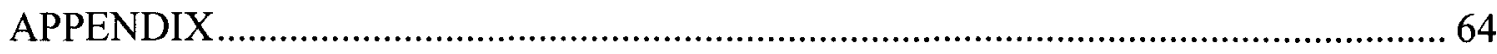

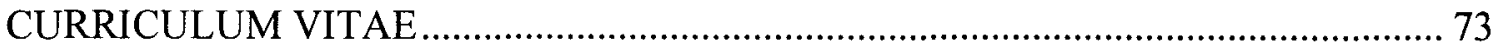




\section{LIST OF FIGURES}

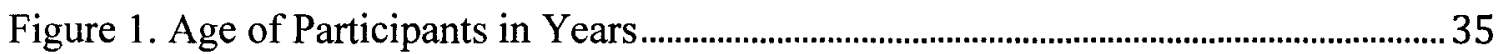

Figure 2. Number of Years Participants Have Played Trumpet...............................................36

Figure 3. Number of Years Participants Have Taken Private Trumpet Lessons ................. 37

Figure 4. Participants' Rating of the Helpfulness of Lessons in the Development of

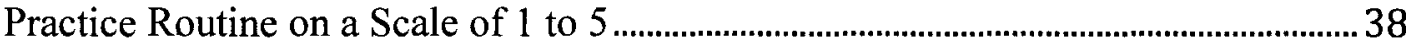

Figure 5. Frequency of Metronome Use During Typical Practice Sessions

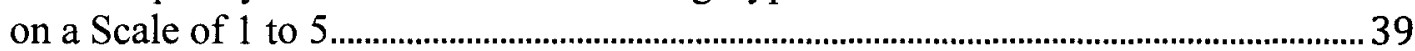

Figure 6. Number of Reported Hours Participants Spent Practicing Last Week................. 40

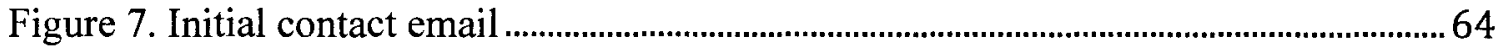

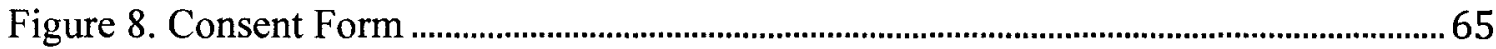

Figure 9. Étude 1: Gallay Unmeasured Prélude No. 21 for Horn ...............................................68

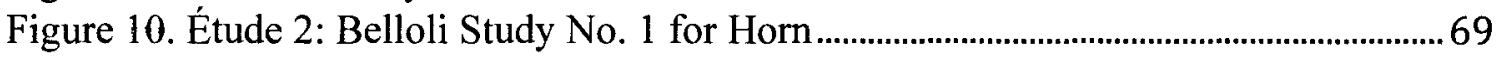

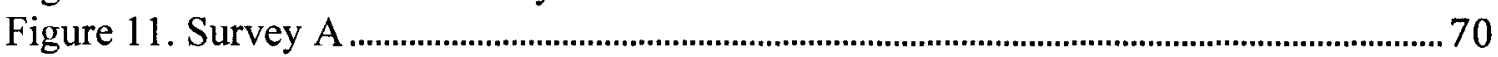

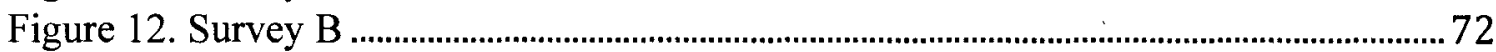




\section{INTRODUCTION}

Musicians are constantly finding ways to improve instruction and learning. In the practice room, this becomes even more evident as each student approaches a new piece of music with or without the guidance of an instructor, bringing learned techniques as well as self-regulated ideas into use. Common questions emerge. What does a student practice first—scales, études, solo repertoire, or something else? In what order does a student practice their materials? How much time does a student spend on each assigned piece? When a student spends more time on one element, is it due to enjoyment or acknowledgement of a need to improve?

Upon considering these indefinite aspects of instrumental practice, other issues materialize. When a student is struggling with a particular section of music, do they revisit the part or spend extra time on it? If so, how much extra time do they spend on that particular problem? What techniques do students use to work out issues?

As soon as it is determined that there are definite distinctions between the methods and abilities of all players, more questions surface. When and where are techniques learned? How much practice time does it take to become proficient? How much practice time does it take to become an expert? Who is responsible for teaching students how to practice? How does a teacher best impart musical knowledge to students of different ages, and students with different learning styles? At what point do students begin thinking and growing independently outside of a teacher's influence? 
Because there are many philosophies on instrumental practice-both pertaining to how it is developed and in what way it occurs with each student—it would be useful to observe individual students in the practice room and see how they approach learning new music on their own. This would help decipher any trends there may be in practice techniques among different students. It would also be noteworthy to discover whether there are some techniques that tend to be more effective than others, and to relate these findings to knowledge about how people learn best.

Delving further, one might wonder whether all students actually share common techniques in practicing, or whether there are infinitely diverse learning styles in the practice room. Are some approaches more prevalent than others? Within any found distinctions, are there trends in age level or experience? Subsequently, when considering age and experience as influences on skill and tactics, can the two be distinctly different?

From these basic tenets, key questions emerge.

- Do music learning and instrumental practice improve continuously with time spent playing the instrument, or is there something that a teacher can do to help the student's process of learning?

- Has the student taken private lessons? If so, how long and how often? Do lessons cause improvement in practice skills?

- How would the student describe their private lessons in relation to their growth as an instrumentalist and musician? 


\section{Purpose Statement}

Practicing music can take many paths. To better understand this, the purpose of this qualitative study is to investigate how four college music students - two seniors and two freshmen--practice as they prepare an étude. From this, it is hoped that some of these questions can be answered:

1. Does the length of playing experience affect how one practices?

2. Does the number of years a player has taken private lessons influence practice techniques used?

3. Does age or experience relate to a player's perception of their practice success?

4. Are their distinctions between the practice behaviors of college freshman and senior trumpet players?

\section{Limitations of the study}

- Small sample size (four participants)

- Possible lack of detail in participants' responses to survey questions

- Measures used to collect data can be interpreted as subjective (surveys and observations of videos) 


\section{REVIEW OF LITERATURE}

\section{Introduction}

There are various elements that comprise a good practice routine. Some are developed in the rehearsal experience, while others are honed in private instruction. The following review of selected literature outlines these key elements and makes distinctions between the importance of classroom learning on an individual's ability to achieve independently, and various factors that help determine success in the practice room. Four areas are investigated in particular. These are the significance and impact of a teacher on one's approach to individual practice; possible correlations between age, experience, and methods used in the music learning experience; the relationship between learning styles and how one is taught to practice; and distinct motivations and approaches to practice.

\section{In The Classroom}

\section{From novice to expert}

Research indicates that a conductor's level of experience directly influences the direction and quality of instruction in the music classroom. Bergee (2005) examined conductors at three levels of conducting expertise-novice, intermediate, and expert. Conductors were asked to describe their thought processes during rehearsals while being audiotaped. The study revealed that the novices focused on superficial items that directly involved conducting, such as rhythm and cues. Intermediate conductors were shown to 
have a better grasp on conducting fundamentals, but like the beginning conductors, did not vocalize to the ensemble. Expert conductors were shown to focus the least on surface conducting aspects, and more on performance items such as balance and style. Two other studies by Goolsby (1999) and Byo and Austin (1994) showed similar results.

The unified outcomes of these three studies suggest that the degree of skill and experience a conductor has influences the conductor's rehearsal methods, and in turn influences the type of instruction the rehearsal receives and how an individual learns music. This leads to questions about whether the age and experience of any musician directly determines the type and quality of his or her individual practice sessions. In order to answer these questions, it is crucial to find connections between ensemble rehearsals and individual performance abilities.

\section{How podium instruction can develop students' musical skills}

While it is challenging to isolate one instructional process in particular, research indicates some aspects of conducting that lead to more proficient musicality, and that may subsequently result in more effective individual practice. Skadsem (1995) demonstrated in a choir rehearsal that conductor verbalization is a more effective rehearsal element than dynamic markings, conductor gesture, and choir dynamic, as they pertain to desired individual singers' dynamic responses while singing. This shows that a conductor's verbal instructions are vital in gaining students' attention and advising students on how to behave and what to do both in the rehearsal setting and alone in the practice room. It could be inferred that the students who learn these positive behavioral skills in the classroom are able to translate them into a more focused and "on task" practice routine. 
In addition to conducting instruction, research reveals definite factors in a rehearsal that contribute to performance. Price (1983) studied an ensemble's reaction to a three-step model of rehearsal. Ensemble reaction was divided into categories of musical achievement, attentiveness, and attitude during rehearsal. The three-step model of rehearsal involved three different conditions or actions involving varying combinations of academic task presentation, conductor reinforcement, and ensemble practice. Findings showed that all three are beneficial, and are most effective when joined together to help a musician learn music. It would be extremely valuable to identify precise factors in the classroom environment that contribute directly to students practicing more proficiently on an independent basis. It may first be helpful to identify what exactly defines a proficient, or successful rehearsal, and to discover trends between students and musicians who do structure their practicing in similar ways and how these transfer to the practice room.

\section{Rehearsal techniques can provide learning tools for students-Structure}

The structuring of a productive music rehearsal is not well understood. Many variables contribute to this, including time use and rehearsal activity. A study by Brendell (1996) examined the use of time as well as student attentiveness (at the beginning of and during) high school choral rehearsals. The study analyzed the correlation between student attentiveness and certain activities. Results indicated that the highest percentages of "off-task" behavior occurred during activities that involved less active participation. This leads to the suggestion that both classroom rehearsals and individual practice sessions should be structured to provide more involved participation opportunities as consistently as possible. These results correlate with the findings of a study by Yarbrough ad Price (1981) that determined teachers who use more performance 
activities in the rehearsal environment achieve more self-motivated contributions from students. Based on the idea that more direct involvement leads to enhanced success, it could be beneficial for musicians to coordinate their individual practice sessions around activities that they find enjoyable in order to more easily remain interested and committed.

Regarding the structuring of a rehearsal during which students remain constantly engaged, many ideas have been recommended. However, no single approach has been conclusively determined as the most effective in retaining student interest and attention throughout the entire rehearsal time. For that reason Cox (1989) sought to determine what rehearsal structure was used by successful choral directors in Ohio. The results of his study indicate that, among successful directors observed, there was one approach that seemed to be the most popular, and there were also similarities in methodology and attitude. This approach involved a rehearsal beginning and ending with activities that are more enjoyable than intensive for students, but with the middle portion of rehearsal being devoted to a more concentrated analytical study of musical pieces. Also common among most of the directors observed was a preference toward doing a complete run-through of one piece before moving on to the next piece.

This knowledge could be transferred to the structuring of individual practice, and could give students insight into making their practice sessions both profitable and enjoyable. It would be very insightful to observe practice routines of instrumental students and determine correlations between structuring and pacing of the individual rehearsal, enjoyment of materials rehearsed, frequency of complete run-throughs of pieces, and success or improvement. Further research is needed to examine the direct 
effect of organizational structure, methods, and type of attitudes on creating a successful and productive rehearsal environment where students gain both technical and musical skills. In general though, it may be significant to understand that beginning and ending a practice session with enjoyable activities, placing the more intensive musical study at the midpoint of the rehearsal, and doing complete run-throughs of pieces before moving on could be the most productive way to structure a practice session.

\section{Rehearsal techniques can provide learning tools for students-Modeling}

A study by Henley (2001) identified two approaches that could be used constructively in ensemble performance, and his findings could be applied directly to practice techniques. This study involved six ensembles, each with their own combination of two conditions. The first of these conditions was modeling versus no modeling. Participants who were provided with a model before performing were more accurate in pitch and rhythm. The second approach involved variances in tempos given by the conductor, but resulted in no significant findings. With the understanding that modeling in particular is a useful teaching tool, students could be more effective in the practice room by utilizing recordings of their instrument or piece, listening to music of different styles, genres, and time periods, and by trying to emulate the sounds music teachers have demonstrated to them.

Modeling revolves entirely around aural development, and is highly significant in many cultures in relation to learning music, and can apply in both the classroom and in an individual practice setting. This theme of aural learning correlates with the Suzuki method (Barber, 1991; Brathwaite, 1988; and Garson, 1970), and is often associated with what is sometimes referred to as "rote learning." The Suzuki philosophy (also known as 
the Suzuki Talent Education Method) uses the concept of learning a language and relates it to learning music. The idea comes from the ease with which language is intuitively learned at a young age - it is a natural occurrence to hear, interpret, and imitate sounds and speech. Conversely, it is not natural to read before speaking. The same is true of music-learning to read notation before learning to listen, sing, and play is not organic. In a practice session, students taught by this method may focus on listening to the music instead of watching it, and on imitating a recording or a teacher's sound. Further research could determine whether find they more performance success than those students who focus more on learning the rhythms and pitches of a notated étude simply by looking at the sheet music.

Cope (2005) found that in a group of 13 adult fiddle learners, 12 of whom had never had taken part in significant musical training or lessons, most had developed a selfregulated aural philosophy of learning. With minimal notational skills, the means by which these fiddlers learn music revolves almost entirely around hearing something before they play it, or improvising based on aural perceptions of key, chordal structures, rhythm, and style. It is important to note the distinction between this type of deep understanding and the type of surface learning students often achieve by only being able to read the notes and rhythms on a page. Although most of them don't actually read music, these fiddlers are able to perceive style and dynamics, frame musical phrases appropriately, and demonstrate comprehensive understanding of musical form-all without having been formally taught these aspects of music in a classroom setting. Less aurally sensitive learners, however, will not pick up on these nuances, but will instead only understand notes and rhythms at a superficial level. This underlines the importance 
of aural learning, which should always be present in the classroom and the practice room in order for students to develop a comprehensive musical understanding.

\section{Rehearsal techniques can provide learning tools for students-Repetition}

Not surprisingly, repetition is a reinforcement technique used by all teachers to more efficiently train students, and it is also one of the most commonly used techniques in individual practice. Repeating an action can hone one's familiarity and ease with a skill or subject. For example, this can be used to perfect difficult passages of musicespecially when the repetition is done strategically. Two articles by Bronfman (2009) discuss a multitude of teaching concepts involving repetition. The purpose of Bronfman's first article was to discuss methods of repetition in the choral rehearsal, and to determine more effective techniques than simply repeating the same fragment the same way each time. The author lists a multitude of ways one can use repetition effectively in a music rehearsal. These include varying syllables and tempo, singing backward, and substituting the words in a passage that has difficult pitch intervals with commonly recognized songs (like "NBC" for "sol mi do"). Students can use many of these ideas to vary their repetition while practicing their instrument.

\section{Rehearsal techniques can provide learning tools for students-Kinesthetics}

The purpose of Bronfman's second study was to continue the original article, and to implement kinesthetic learning — a key element of practicing -as well. One key point in both of Bronfman's articles is that while the use of repetition is a beneficial approach, there is a high necessity for variety in any learning situation. Not only will this sustain student interest - it will more likely appeal to a greater proportion of the many learning styles that may be present in any classroom. The notion of using kinesthetics in the 
music classroom is widely attributed to Emile Jaques-Dalcroze, who believed in developing hand-eye-body coordination as a secondary skill along with music. He often used the term "eurhythmics," which incorporates movement with music and time. Jean Piaget, another prominent figure in the music education genre, agreed that children learn best when actively participating and moving to music. This idea could prove beneficial to instrumental students in the practice room, if they are able to combine physical movement with their playing.

This concept of movement with music can be directly connected to the previously mentioned Suzuki method (Turpin, 1986). The core of Suzuki's method, while stressing audiation, embraces ten basic facets of a child's learning stages. Alfred Garson once asked Suzuki which of the ten points he believes is the most important. Suzuki's initial answer is that they are all important because they interrelate, but he then went on to say that if one had to be at the top of the hierarchy, physical movement would supersede the others. This is because physical movement is the component that is most instinctive to humans-after all, a baby is able to move naturally even before birth (Garson, 1973). Based on the advances in the understanding of learning by Dalcroze, Piaget and Suzuki, teachers can assume that using repetition and kinesthetics together in a multitude of diverse ways will bring the most success.

Because these prominent music education theorists agree that repetition, movement and aural skills are all important to musical learning, it can be certain that students who use these ideas in practice may be more successful. These philosophies, expanded by the ideas of Bronfman's studies, can be directly transferred to students 
working individually in a practice room. Further research might discern effectual ways for students to incorporate physical movement into practice room activities.

\section{Understanding learning styles}

It is widely accepted that there are many well-defined styles of learning, and that every person is best suited to a distinct blend of these ways of learning. The three learning styles recognized by the Briggs-Myers model (Myers, 1985) for instance include auditory, visual, and kinesthetic/tactile. These relate directly to the aforementioned research. Playing a musical instrument requires the use of all three of these primary sensory skills, so it is important to cultivate them all in order to succeed as a musician. Still, since each person learns differently, teachers should try to balance their methods of teaching to find the best combination of styles that are the most effective for individual students. In a large classroom setting, this can be challenging. However, in a studio oneon-one setting, teachers are able to aptly target learning with techniques explicitly designed to hone the student's predominant learning style(s). With this approach students can tailor their own practice sessions to be as productive as possible based on their individual needs and strengths.

In contrast with the Briggs-Myers model, Zhukov (2007) suggests that the term "learning style" has not distinctly been defined. Zhukov argues that instruments typically used to assess learning styles in students are fundamentally flawed, and in her study she seeks to discover a more accurate means of assessment as well as ascertain more precise classifications of learning. The results of her study provide alternative insights into how people learn, and suggest different interpretations of the learning styles of advanced musicians. Her ideas can be used to enhance the means with which teachers 
accommodate students' learning needs, and could help individual students realize and understand their own unique learning needs when they are on their own practicing. In agreement with the priorities of both the Briggs-Myers model and Zhukov, Beheshti (2009) proposed that in a one-on-one setting the best way to cater to student learning is to first determine the student's learning styles, and then design lessons around them. In this study, many instrumental teaching techniques were listed that clearly coordinate with at least one of the three main learning styles. The compilation of techniques that resulted from this study may lead to new knowledge on how to best serve students' learning needs, and can help teachers to give students the tools practice efficiently and effectively. Further research on this topic could make connections between students' observed or known "most successful" learning styles and related techniques the students use in the practice room.

Carl Rogers, a specialist in therapeutic counseling, was firm in his belief that students must have foundations in their musical knowledge before they can develop their self-evaluation skills, creativity, and independence. Rogers believed that the teacher's role is to facilitate the students' musical growth and confident critical thinking so they can become independent and be capable of learning on their own. The teacher is to provide structure, but not be the primary source of learning (Shehan, 1986).

Taken together, a foundation of knowledge learned in the classroom or one-onone studio setting combined with skills developed in a private practice session should produce the best opportunity for success for the instrumental performer. Correct fundamentals learned from a teacher, effective habits taught in a positive learning 
environment, and personal understandings of different approaches that affect one's ability to learn are essential to fostering the most productive practice routine.

\section{Individual Practice: Innate Talent, Motivation, Time Spent And}

\section{Quality Of Learning}

\section{Musical expertise requires more than practice}

Ruthsatz, Detterman, Griscom and Cirullo (2007) address the theory that expertise in any field is possible for an individual who accumulates "sufficient deliberate practice." They go further and suggest that existing innate talent also plays a role in whether an individual is able to achieve expertise, and question whether the existence of innate talent varies the ease with which a person improves on his or her instrument. In their study, these researchers compare audition scores, recorded practice time, and scores on Gordon's Advanced Measures of Music Audiation $(1986,1992)$ and Raven's Progressive Matrices (Raven, Court, \& Raven, 1998). Results indicated that practice alone was not as significant as correlations between the musicians who scored higher in general intelligence and audiation, and had higher levels of practice time. This study did not disprove the theory that expertise can be achieved by anyone. Nonetheless, its results provide evidence that it may be easier for students with higher levels of innate musical skills to attain a level of expertise regardless of practice routine.

As the previous study debates the line between practice time and innate talent, Symunds and Chase (1992) argue for the moderation of practice and motivation. In their research they asked, "Regarding practice and motivation, which is more important?" The researchers decided that there are two schools of thought pertaining to the answer; but 
that regardless of ranking, the two elements go hand in hand. Motivation is what causes a student to practice, but only by actual practice does a student improve. Symunds and Chase outline two arguments - the first being that with enough practice, knowledge or skills can be learned. The second school of thought believes that with proper motivation, the same can be achieved. While it is true that one or the other can prove to be more applicable to certain circumstances, they are both equally important parts of learning. Practice and repetition enable a learner to drill in something enough that it can become effort rote knowledge or become part of one's muscle memory. Motivation gains a learner's interest and enables the learner to develop knowledge or skills perhaps more easily or quickly than they would be developed otherwise. Motivation and practice must be paired together in order to attain the highest level of learning possible.

\section{Motivation to achieve and attitudes regarding practice}

Motivation for academic excellence is another factor in the practice time of music students. In a study by Smith (2005), college instrumentalists were surveyed on their practice routines, and the desire to excel while learning music. Smith found that there are discrepancies in motivational factors among students, but that in general, academics were an important contributor to musical success. Smith also found that orientation of motivation-task-related versus ego-related can significantly affect practice performance results. According to the results of this study, when goals orient around ego (defined as "demonstrating high ability relative to others"), student focus is shifted from full engagement with the task to thoughts about social importance. This focus tends to be associated with negative affect when failure occurs, anxiety, and surface learning. 
In contrast, when goals are oriented around tasks (based on self-improvement instead of competition with others), there are more associations with positive affect, intrinsic motivation, deeper processing strategies, and healthy challenge seeking. From these findings, one can see that when motivating students in practice, it is important to apply goals directly to the tasks at hand. While Smith's findings focus academics and task-related motivation as essential to a student's achievement, further research identifies other motivational factors that directly effect the practicing of music students.

Another important motivating factor in instrumental music practice is enjoyment. Hyllegard and Bories $(2008,2009)$ found in two related studies that students who enjoy practicing are more likely to be successful. The results of these studies determined that there is a difference in success among students who practice deliberately out of enjoyment, and students who practice routinely without personal enjoyment. As with academic excellence, additional research is needed to determine disparities in practice sessions that are based solely on one of these two elements.

A study by McPherson and McCormick (1999) examined two self-reported components of musical practice-motivation and self-regulation. McPherson and McCormick administered a survey to 190 pianists prior to an intense performance examination and determined that the amount of practice reported before the performance directly related to the amount of technical work they did as well as the level of anxiety they experienced immediately before performing. Results of the survey also indicated correlations between the pianists' reported answers with regards to greater practice time, greater amounts of informal/creative practice, greater amounts of repertoire worked on, 
and greater amounts of technical work. Findings suggest that a deeper engagement in preparing for a musical task relate to more efficient self-regulated musical habits.

Schatt (2011) explored high school band students' perspectives of practice, and attempted to ascertain their attitudes toward practice and how their attitudes affected practice motivation. Schatt determined that internal perceptions of ability and effort correlated highly with attitudes toward practice. Based on these findings, teachers could make assumptions that if students are given sufficient positive reinforcement to uphold their self-perceptions, they may find practicing to be more fun.

\section{Practice time}

Stambaugh and Demorest (2010), suggest that the scheduling of practice sessions may have an impact on performance and success in the practice room. Their study investigated the effects of practice schedule on wind instrument performance. The results of their study suggest that a regular practice schedule can be highly beneficial to the success of wind instrument players. More inquiry is needed in order to make a judgment on which, if any, practice scheduling approaches yield the most improvement among musicians.

Conversely, other research suggests that there is no perceived difference between practice sessions that are scheduled in a "blocked" order, and those that are random. In a study by Stambaugh (2011), young instrumental students were observed under different practice conditions. Some practiced in a preplanned, blocked format with repetitions and full runs of music predetermined. Others practiced randomly, working at their own pace and volition. The results of this study indicated that there was no difference in the end 
results of the different practice sessions. The content of the practice session was shown to be more important than when and how often practice sessions occur.

Like the current study, Byo and Cassidy (2008) observed time use in the practice of college music majors and compared it to the students' self-reports. They asked students to articulate specific techniques they used while practicing. Byo and Cassidy discovered that while most of the students listed many common techniques, very few of them actually used the given techniques productively. This suggests a gap between "knowing" and "intelligent doing." The findings of this study by Byo and Cassidy could be linked with a study by Dorfman (2010), which determined that even with pre-service teachers, self-perceptions of time use in the classroom are typically not accurate when compared with their actual observed behaviors. With these correlations, it may be practical to admit that perceptions of both time use and quality of learning can be skewed.

There is further evidence of inconsistencies in musicians' perceptions of their own practice time. Madsen (2004) investigated whether musicians accurately remember how much they practiced in the past, and whether the actual time spent practicing is related to how successful as musicians they are later in life. Madsen found that people do not accurately recall their memories of practice time and also that there is no strong relationship between practice time and later musical success. It is still undecided if the amount of time spent practicing has a direct positive effect on later improvement and success, although Jorgensen's study (2002) discusses the relationship between the amount of instrumental practice and level of instrumental achievement and results of this study do indicate that there is a positive relationship between current practice time and instrumental achievement. 
In addition to discrepancies between self-perception and actual observations in the practice room, research indicates that there are incongruities among observed practice behaviors, self-reported practice efficiency, and performance achievement of young instrumentalists. Like the present study, Miksza (2007) studied students' instrumental practice sessions and also collected student-reported data about their practice sessions. After comparing the observations and the student-reported data, Miksza determined that the students' perspectives of their own practice sessions were not completely accurate. More inquiries into this topic might distinguish cause for such inconsistencies in musicians' individual perceptions of their efficiency and achievement.

\section{Self-evaluation: accuracy and impact on performance}

Hewitt's work (2011) sought to determine correlations between self-evaluation of instruction, accuracy of self-evaluation, and music performance among middle school instrumentalists. His results suggest that instruction in self-evaluation had no significant effect on either accuracy of self-evaluation, or performance. It seemed that age did positively affect performance to a slight degree. The author suggests that students may need more time to learn to self-evaluate more effectively. This could be a skill to be taught in classrooms, although whether it can be used successfully will require further inquiry. Self-evaluation can be a valuable tool in streamlining practice sessions and in creating focus so that students are more successful in learning.

Miksza (2012) attempted, with some success, to develop a means to accurately measure self-reported practice behavior in students. This assessment may prove useful in the future for students using self-regulation and self-assessment strategies in the practice room, and could also be combined with teacher guidance to maximize improvement 
potential. This work has a direct relation to the current study because Miksza is also interested in determining what strategies students use when practicing, and how they perceive their actions in the practice room.

A study by Vaughan (2002) asked students to keep a journal of their practicing, and to record any methods and music analysis techniques used. Vaughan found that the student used varied systems to analyze their music, ranging from Schenkerian concepts to more basic ideas about rhythm and melody. Vaughan concluded that the influence of a teacher played a tremendous role in the mental and physical processes used by a student in the practice room. With this knowledge, it can be assumed that teaching a student effective practice procedures can result in more success.

\section{Teaching how to practice}

Kostka (2004) points out that instrumental students frequently struggle with learning an instrument, conquering new repertoire, mastering proper techniques, and knowing how to accomplish it all efficiently. Teaching students how to practice can aid them in overcoming all of these difficulties. Instead of allowing students to become frustrated and overwhelmed with stress because they aren't able to achieve what is expected of them, teachers can provide them with the tools they need in order to create the best practice sessions they can when they are on their own.

Christensen (2010) observed the practice behaviors of two eighth grade instrumentalists in a similar design to the current study. From observations as well as information gained during interview sessions with both the parents and the eighth grade participants, Christensen concluded that practice description and practice actions do not always equate, and that there is a gap between students' knowledge and students' ability 
to effectively apply strategies to their practice routine. Further research could improve knowledge on how to teach students to practice strategically.

In her 2004 article, Kostka refers to a few simple concepts that teachers should keep in mind when teaching musicians how to practice effectively. These ideas coincide with a similar study by Oare (2011). The two studies caution teachers to be sure that the student understands the concept of practicing effectively so not to waste time and effort. Teach them how to structure a practice session from beginning to end, and how to manage time as efficiently as possible. Teach students how to best spend their time in the practice room, and give them techniques they can apply successfully, without guidance, toward the materials they are learning. Direct them in how to work through difficult passages, focusing on self-assessment, correct repetition and slowing tempos. Teach them how to listen, and give them recordings to emulate. Balance fun repertoire with necessary technique-building materials. Enable them to build their practice routines around what they can achieve successfully, e.g., if they need to take breaks, then they should take them.

All of these are ideas that any teacher can incorporate into lessons and classroom instruction so that when the student is alone in the practice room, they have the tools they need to be successful. However, with research supporting knowledge that teachers do not consistently provide tools for practicing successfully, it is not clear where, when, or how musicians of varying levels acquire these self-regulating skills.

\section{Self-regulated practice behaviors}

In the classroom, it is a teacher's responsibility to provide students with the tools they need in order to develop their self-regulating strategies. Butler (2002) defined self- 
regulated learning in a series of steps. Firstly, self-regulated learners will analyze the demands of a task. They will then think through any instructions, notes, or known information pertaining to the task. The next step will be to create a strategy. This may involve using methods that the student has used successfully in the past. As the selfregulated learner proceeds through the task, he or she will monitor outcomes of strategies and adjust accordingly when a particular method is or is not effective. Butler's article determined that there are many theoretical instructional principles that can be used effectively to cultivate self-regulated learners in the classroom, but that it is important to provide support during the learning process and promote self-efficacy in learners.

A study by Nielsen (2004) investigated learning strategies of advanced music students and determined the relationship between their self-efficacy beliefs and the strategies they actually employ during practice. Self-efficacy is defined as 'people's judgment of their capabilities to organize and execute the courses of action required to attain designated types of performances (Bandura, 1986)." Nielsen's study focused on the way in which students practice their instruments, and found that students with higher self-efficacy were more involved in trying to learn the practice material well than students with lower self-efficacy.

As mentioned previously when discussing self-regulated learning, research indicates that productive individual learning in a practice room is a skill that is developed over time, with experience and guidance. Because of this knowledge, it is assumed that many young musicians will not yet have the tools they need in order to practice efficiently. Austin, Berg and Haefner (2006) discovered that in a group of sixth grade band and orchestra students, many have not developed any strategy for practice at all. 
This indicates that it is of utmost importance in the music classroom to actually teach students how to practice.

Other studies have revealed that advanced musicians use sophisticated and selfregulated rehearsal strategies in their practice sessions, including self-evaluation, problem solving, and strategic planning. A study by Leon-Guerrero (2008) sought to determine which self-regulation strategies are implemented by adolescent instrumentalists during practice. Repetition was found to be the method most commonly used by these young musicians. However, it is still unclear whether young players use given techniques in the same manner. Further research in this area may determine how and when musicians gain their individual rehearsal strategies.

In a study by Nielsen (2001) that was a follow-up of his 1999 study, students were again observed in their practice. As in his earlier study, Nielsen looked for learning strategies and self-regulation. However, he took his initial inquiries further by guiding the students in different effective approaches and testing for how much self-regulation they used. Results showed that this guided approach was very successful, and the students demonstrated advanced self-regulation strategies that also resulted in improvement.

In a later study, Nielsen (2008) surveyed achievement goals of music students and how their strategies and instrumental performance relate to those goals. The results indicated that students tended to mostly be oriented toward task-related goals, but also toward ability-approach related goals, instead of ability-avoidance related goals. This implies a leaning toward positive reinforcement and a positive outlook. 


\section{Quality of practice}

It is now understood that when it pertains to instrumental practice, quality and content are more significant than quantity. Duke, Simmons, and Cash (2009) investigated the practice method of 17 advanced college pianists under very controlled circumstances. As in the current study, the players were given the same short excerpt and told to practice it until they felt it was comfortably learned. Their practice was recorded, observed, and analyzed for time use, technique, and repetitions. They then performed it later as a retention test. Findings indicated no significant relation between the best performances in the retention test and time spent practicing. However, there was significant relation between those who practiced with the most correct repetitions and those who performed correctly. The issue of content in the context of instrumental practice sessions is continuing to be investigated by researchers, but with the knowledge gained by this study it can be assumed that repetition used correctly as a practice technique can certainly be effective for students.

In another study, Miksza (2011) investigated relationships between observed deliberate practice behaviors and performance achievement in college wind players. His study, like that of Duke, Simmons and Cash, also explored relationships between observed practice behaviors, performance achievement, and individual differences in impulsivity and achievement goal motivation. Results of the study indicate that students who practice more deliberately tend to pursue fewer impulsive actions in the practice room, and also that among these same students there were significant positive correlations between performance achievement and certain observed practice techniques 
(such as "repetition," "whole-part-whole," "chunking," "slowing," "chaining," and "use of a metronome").

Pedrick (1998) came up with a five-step model that, when used, can maximize students' success in the practice room. This model included: set up, preparation, warmup, maintenance and advancement. Essentially, Pedrick determined that no aspect of playing should be neglected, including the time spent outside of the practice room and time spent even thinking about playing. Further research into these steps could determine whether they are fully inclusive, and whether students following this model can achieve more success than students not following this model.

Like Pedrick, Peterson (2001) attempted to determine specific steps to achieve practice routines. In his work, Peterson investigated three distinct tactics that can be used for practice improvement. Following along the lines of the Suzuki method, these three strategies involved: including the parents in all levels of learning; creating and following a practice plan; and attempting to meet national standards for improvement and excellence. Further study could determine how significant these three ideas are in the process of developing the most successful practice behaviors in instrumental students.

Following along the same lines of thought as Pedrick and Peterson, Tatton (1997) listed similarly effective practice techniques that students should use. These include:

Stressing quality over quantity, having a regular routine, being prepared with all necessary items, having goals and a plan to accomplish them, following the plan and taking pride in accomplishing set goals, using proper posture, practicing slowly, using repetition and stay mentally involved, not repeating errors, but practicing correctly five times to erase them, separating difficult passages into smaller and more manageable chunks before piecing them back together, not neglecting "easy" music, using a metronome, recording practice and listening back for ideas on improvement, using a mirror to check posture/technique/position, and 
balancing practice time to cover all necessary areas such as repertoire, technique, intonation, scales, special techniques, etc.

Further study on the matter could determine whether there are positive correlations between students who use any these strategies, and levels of resulting improvement.

One of the more notable practice techniques mentioned by Tatton was that of separating difficult passages into smaller pieces that are more effectively managed. This is also known as "chunking." A study by Pike and Carter (2010) examined the effect of different types of chunking in piano students' practice and determined that chunking passages with both a rhythmic emphasis and a pitch emphasis is helpful in learning difficult pieces of music correctly. Students should incorporate this "chunking" technique into their practice instead of playing longer passages and passing mistakes with minimal notice. This technique could reduce the time needed to learn a piece a music by making practice more efficient.

Rohwer and Polk (2006) surveyed and observed eighth grade instrumental musicians in order to determine relationships between the number of practice strategies the students could catalog and their performance improvement scores, and also to identify trends in their practice behaviors and compare their achievement based on their actions in the practice room. Rohwer and Polk determined four categories of practice behavior: "holistic, noncorrective practicers, who did not stop for errors in their run-throughs; holistic, corrective practicers, who stopped only for errors in their run-throughs; analytic, reactive practicers, who stopped to remediate sections of music; and analytic, proactive practicers, who jumped around in the music to fix errors."

Rohwer and Polk (2006) found differences between the holistic and analytic practicers; between the pre-performances and post-performances; and also between 
practicers and performances. They determined that the analytic practicers improved more than the holistic practicers did. These findings can influence views on what sorts of behaviors make a practice session more productive. Relating this to the current study, teaching students to practice analytically could be critical in order to provide them with the best means to be successful when they are alone in the practice room.

Byo (2004) explores inefficient practice methods to provide insight into what practice procedures are least helpful, and which can actually be detrimental. One of the most necessary motives to practice is to solve performance problems, but inadequate practice skills can result in lack of progress. Byo examines problem solving in instrumental practice and attempts to resolve the impression that many students do not have the skills to problem solve adequately on their own. Common ineffective student solutions to problem areas are: skip the problem and move on; focus entirely on areas that are easy or fun to play-the areas that do not need to be practiced the most; or play a passage incorrectly multiple times, and move on immediately once it is played correctly one time. Not only do these methods ignore the performance areas that need the most work - they cause a development of adverse habits and disregard learning methods that are known to be more efficient, such as correct repetition. Teaching students proper habits is important so that they are able to be effective without guidance. Additional study is needed in order to determine the best approaches to teaching productive practice behaviors, but first it is necessary to understand what factors contribute to constructive practice.

As mentioned earlier, the differences in the practice sessions of musicians can be difficult to catalog. Research has identified multiple learning strategies that are effective 
in preparing for a performance. Similar to the present study, a case study of two organ students by Nielsen (1999) identified and investigated some of these practice room strategies. Nielsen found that the two students used varied techniques to learn a piece of music but more importantly, they focused on their distinct strategies for different amounts of time. For example, when isolating portions of the piece to improve, both students worked on one large section, but each chose a different section as a priority. Then, one student focused on chords while the other focused on tempi. This study focused heavily on how to obtain and record the data on different levels of learning that take place during practice. Further research may use the findings of this study to determine what practice techniques work best for students.

\section{Variety in the practice room}

One practice method in particular has been proven to be successful. Mentioned earlier when discussing Bronfman's articles about repetition, the idea of variety in any learning situation is vital. Variety sustains student interest and targets a multitude of learning triggers in students. Doris da Costa (1999) studied a group of students in their practice behaviors under two conditions. The first condition involved students using straight repetition of small phrases when encountering problem areas during practice. The second condition involved using a diverse assortment of repetitive techniques that were predefined and followed by students in their practice. Results indicated an astounding positive trend toward the varied structure of repetition versus the straight repetition that the first group used. These findings suggest that varied routines could be more productive than those using the same techniques on a regular basis. 
Dos Santos (2010) did a case study on three piano students at different college levels using Elliot's musical knowledge model (Elliot, 2005). The five forms of Elliot's musical knowledge (formal, informal, impressionistic, supervisory and procedural) allowed Dos Santos to identify distinct strategies used by the pianists in their practice sessions. With observations and interviews Dos Santos was able to determine distinctions linked to which level in school the students were (the students were in their first, fifth, or eighth semester). The five forms of musical knowledge were found in each student's practice behaviors or responses about their preparations, and results indicated an increase in knowledge and ability with increased experience in school. The following study continues the pursuit for more information about whether advanced experience and exposure to teaching influence effect the way a student practices.

\section{Summary}

It is apparent that students learn and practice music in a variety of ways. They take cues from their conductor's model and rehearsal strategies. They learn best by structuring practice around enjoyable material and by using repetition and variety. It is also clear that a mixture of learning styles must be accommodated in an effective practice session in order to encompass all aspects of learning an instrument. The current study takes this knowledge into account and strives to determine what practice strategies are used by college trumpet players, and to decipher whether there are distinctions between the practice methods of freshmen and seniors. 


\section{METHOD}

The purpose of this qualitative study was to investigate how four college music students—two seniors and two freshmen—practiced as they prepared an étude.

Four students participated in this study. These students consisted of two freshman and two senior trumpet players. Because there were only two freshmen and two seniors in the trumpet studio, all of the trumpet players meeting the grade level qualifications were automatically invited to participate via a mass email (Figure 7). Once these four students agreed to participate, they each met with me individually for five minutes to discuss the study and sign a consent form (Figure 8). During this initial meeting with each participant, two additional individual meeting times were scheduled in order to complete the study. These additional sessions were planned to last approximately twenty-five minutes each.

Participants were instructed to arrive at each session already warmed up and ready

to play their instrument. They were also instructed to bring any tools, supplies, and practice aids that they use on a regular basis during their normal practice routine.

\section{INSTRUCTIONS GIVEN BEFORE FIRST SESSION:}

Please arrive at your first session on the date and time we have scheduled. Come a few minutes early if you have any questions. Be warmed up and already prepared to begin playing. Bring with you your trumpet as well as any supplies, tools, and practice aids that you utilize in your typical practice sessions or when learning a piece of music. For example, these might include a pencil, metronome, tuner, audio recorder, Berp, breathing device, or mouthpiece visualizer. When you do arrive, you will then be given an étude to learn to the best of your ability, and instructed to use your own approach to learn it. You will have fifteen minutes, and you will be videotaped. At the end of the fifteen minutes, you will then be given a 
short survey to complete inquiring about your approach. This survey should take approximately ten minutes to complete. This will conclude your first session. You will then complete one additional session exactly like this at the time we have scheduled. Do you have any questions?

Sessions took place in a practice room at the School of Music of a major urban university in the Midwest. Each session with every participant was done in the same practice room with the same type of furniture and default set up. There was one chair, one music stand, a piano with a bench, and a wall-mounted mirror available for the participant's use during each session.

Upon arriving for each session, participants were given an étude and instructed to prepare this étude to the best of their ability using their own approach. The sessions were videotaped. The following directions were given to each student at the beginning of each session.

INSTRUCTIONS AT EACH SESSION:

I am going to give you an étude to prepare. You may play a few notes to adjust to the room if you like. When you are ready, I would like you to look at the étude and learn it to the best of your abilities. You will have fifteen minutes to proceed through this task, and it will be videotaped. After that time, I will stop you and hand you a short survey asking you a few questions about how you approached your task. The survey should take you about ten minutes to complete. Are you ready? Here is the étude.

The étude was then placed in front of the participant, and the researcher left the room for fifteen minutes while the participant practiced. The études are found in Figures 9 and 10 of the Appendix.

The étude given during the first session was an unmeasured horn prélude by Jacques-Francois Gallay. It is No. 21 in a collection of 39 études, Gallay Unmeasured Prélude Op. 27. It was chosen because, as a horn étude it is unlikely that these trumpet 
players have seen or played it. It is mostly unmetered and unmeasured, although there are a few bar lines in the piece to indicate phrasing suggestions. The étude incorporates many stylistic elements but is very ambiguous on tempo, meter and style, and leaves opportunities for a great deal of musical freedom.

The étude given during the second session was a horn étude by Agostino Belloli. It comes from a book of 24 études. This étude, also chosen because it is a non-trumpet oriented work, was selected in particular for its variety of material. It is 53 measures long and unlike the Gallay, provides many articulation and stylistic markings as a foundation for the player's interpretation. The stylistic marking at the beginning is dolce and throughout the étude many dynamic suggestions and breath marks are listed. One interesting aspect of this étude is that it incorporates a pedal "C" tone, which is below the trumpet's natural range. This étude was chosen despite the inclusion of this note, which forces the player to make a choice - to play and lip it down, to leave it out, or to substitute another note.

At the end of the fifteen minutes of practice time, the researcher re-entered the room and gave the participants instructions for the completion of a survey. This survey inquired about the approach the participant took to learn the étude. The surveys are found in Figures 11 and 12 of the Appendix.

INSTRUCTIONS FOR COMPLETION OF THE SURVEY:

Please fill out the following survey to the best of your ability, answering each prompt. You may be as concise or detailed as you deem necessary, but please provide any information you feel is relevant to the questions asked. You are not expected to fill the entire page, but if you need more space simply continue on the back of the page. 


\section{Materials}

To undertake the project, the researcher prepared the practice room with the following materials:

- 13" MacBook Pro webcam (PRIMARY VIDEOCAMERA USED)

- Sony Handycam DCR-DVD650 camcorder with mini Sony DVD+RW discs (BACKUP CAMERA)

- Canon Rebel T3i D-SLR camera (BACKUP CAMERA)

- Samsun L210 digital camera (BACKUP CAMERA)

- Pencils and pens

- Paper copies of études (Gallay Unmeasured Prélude No. 21 for Horn and Belloli Study No. 1 for Horn), consent forms, and surveys

- Practice room: chair, stand, piano, piano bench, mirror

- Stopwatch

- Participants used their own instrument and practice tools (i.e., trumpet, metronome, tuner, Berp, mouthpiece).

At the conclusion of each session, the researcher thanked the student participant. Data was then analyzed, as described in the following section. 


\section{RESULTS}

This study observed four college trumpet players as they prepared two different études during two separate practice sessions. Another component of the study involved answers obtained through a survey at the end of each practice session. Of the four players, two were seniors and two were freshmen. Results indicated that each student answered differently on the surveys, but also that they used different methods during the process of learning the études. While there were some similarities and differences between the answers of the seniors and freshmen, when comparing the surveys to practice behaviors it became apparent that there are connections not necessarily with age but with private lesson experience. The following figures illustration the participants' survey answers. 
Although the freshmen were the same age, it is important to note that the seniors were two years apart in age. Figure 1 illustrates the students' age in years. One of the seniors is older than the other senior because he took a one-year hiatus from school. Each senior has been in college for exactly four years though. Each freshman is completing their first year of college.

Figure 1. Age of Participants in Years

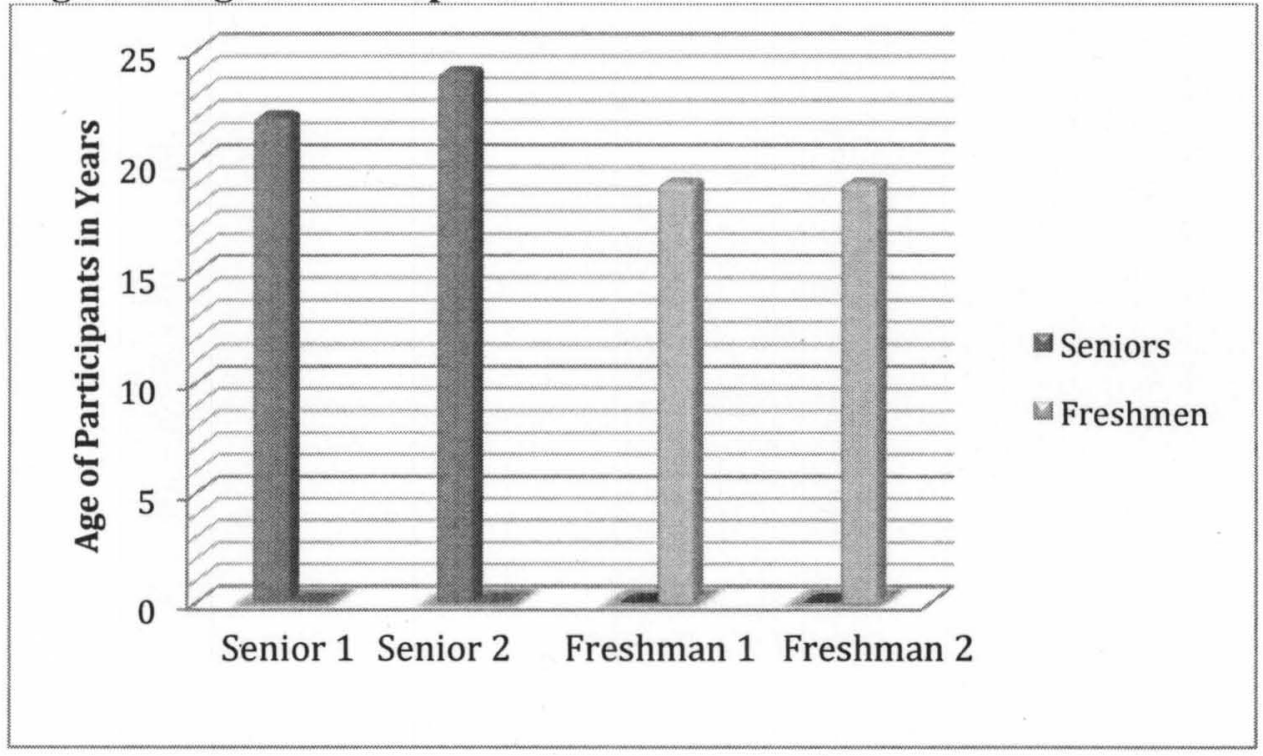


From survey answers and conversations with each of the participants, it was discovered that each student began playing the trumpet in the sixth grade (Figure 2). This is a common beginning level in Kentucky public schools. Because of their similar playing beginnings, a comparison can be more accurate.

Figure 2. Number of Years Participants Have Played Trumpet

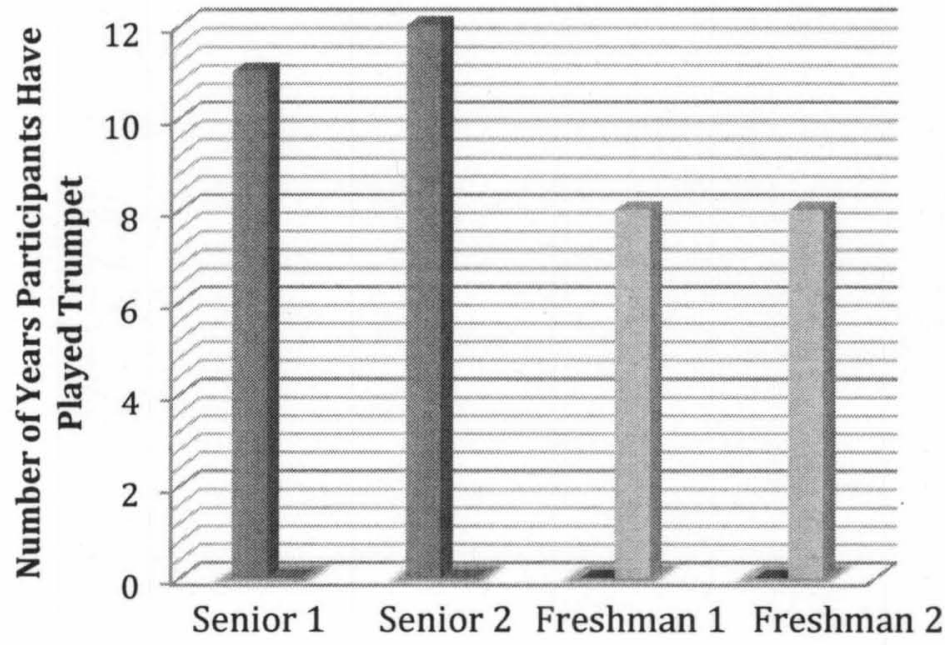

Seniors

Freshmen 
Also through both survey answers and conversations with the participants, it was found that each student began taking lessons at a different stage during their trumpet playing history. Each student did begin lessons at some point in high school. This is illustrated in Figure 3.

Figure 3. Number of Years Participants Have Taken Private Trumpet Lessons

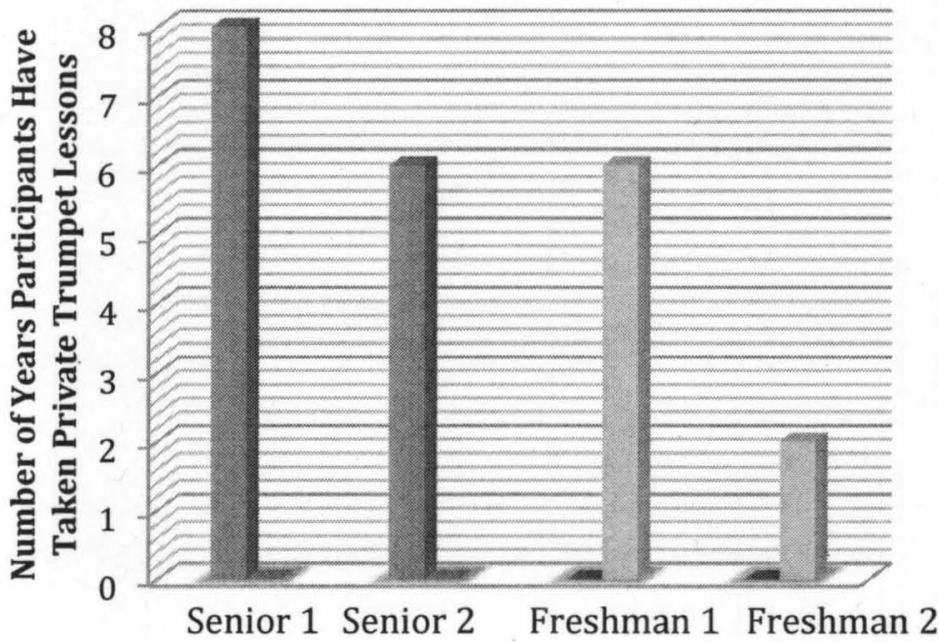

meniors

areshmen

Senior 1 Senior 2 Freshman 1 Freshman 2 
The player who had only been taking trumpet lessons for a total of two years was the only participant who rated the "helpfulness of lessons" at a level of 3 out of 5 possible points. Without further inquiry and discussion with the participant, it is impossible to make assumptions as to why this is so. Possible explanations for this discrepancy could be related to the inconsistency of the lessons because of the large gap in between the two years he listed having studied privately with a teacher. Each participant's rating of the helpfulness of private lessons is illustrated in Figure 4.

Figure 4. Participants' Rating of the Helpfulness of Lessons in the Development of Practice Routine on a Scale of 1 to 5

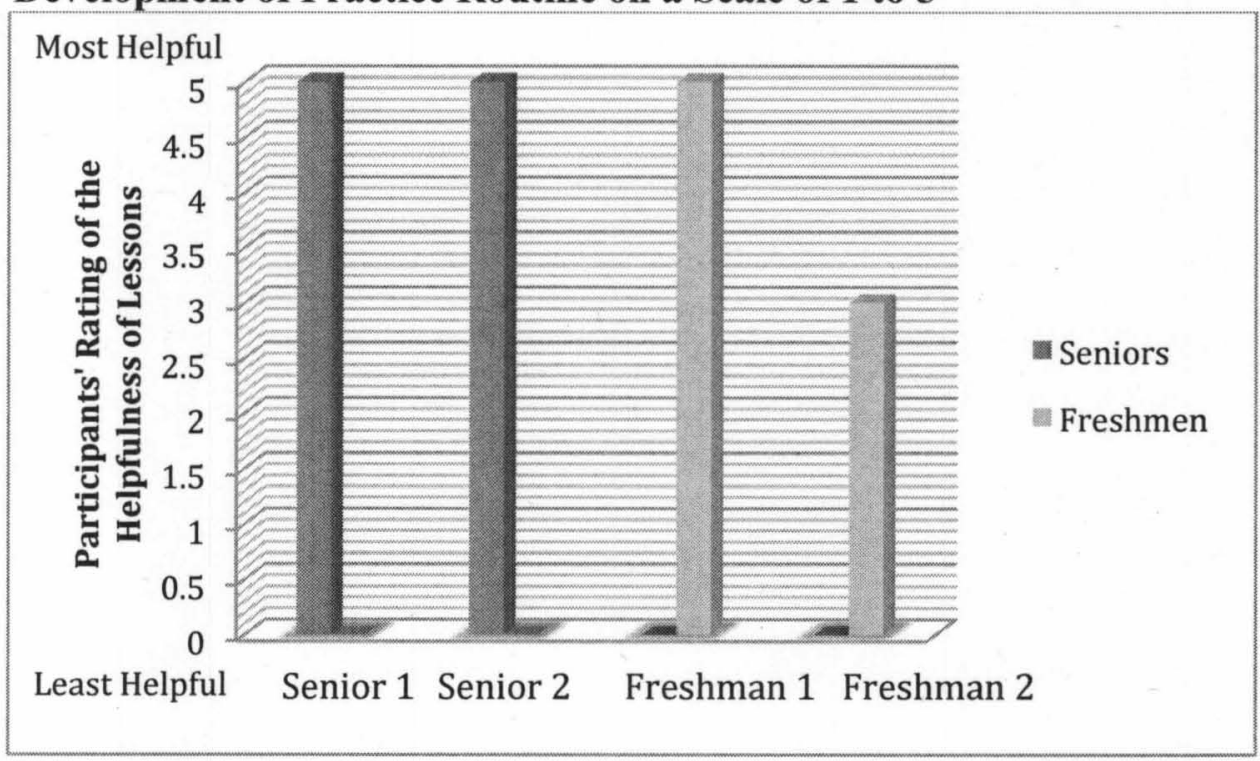


There were no important correlations between practice time, experience on the instrument, experience with private trumpet lessons, and the use of a metronome during practice on a regular basis. However, it is again interesting that the participant who rated metronome use at the lowest frequency is the participant who recorded the fewest years taking private lessons and the lowest rating of the helpfulness of trumpet lessons. The frequency of each participant's use of a metronome during practice is illustrated in Figure 5 .

Figure 5. Frequency of Metronome Use During Typical Practice Sessions on a Scale of 1 to 5

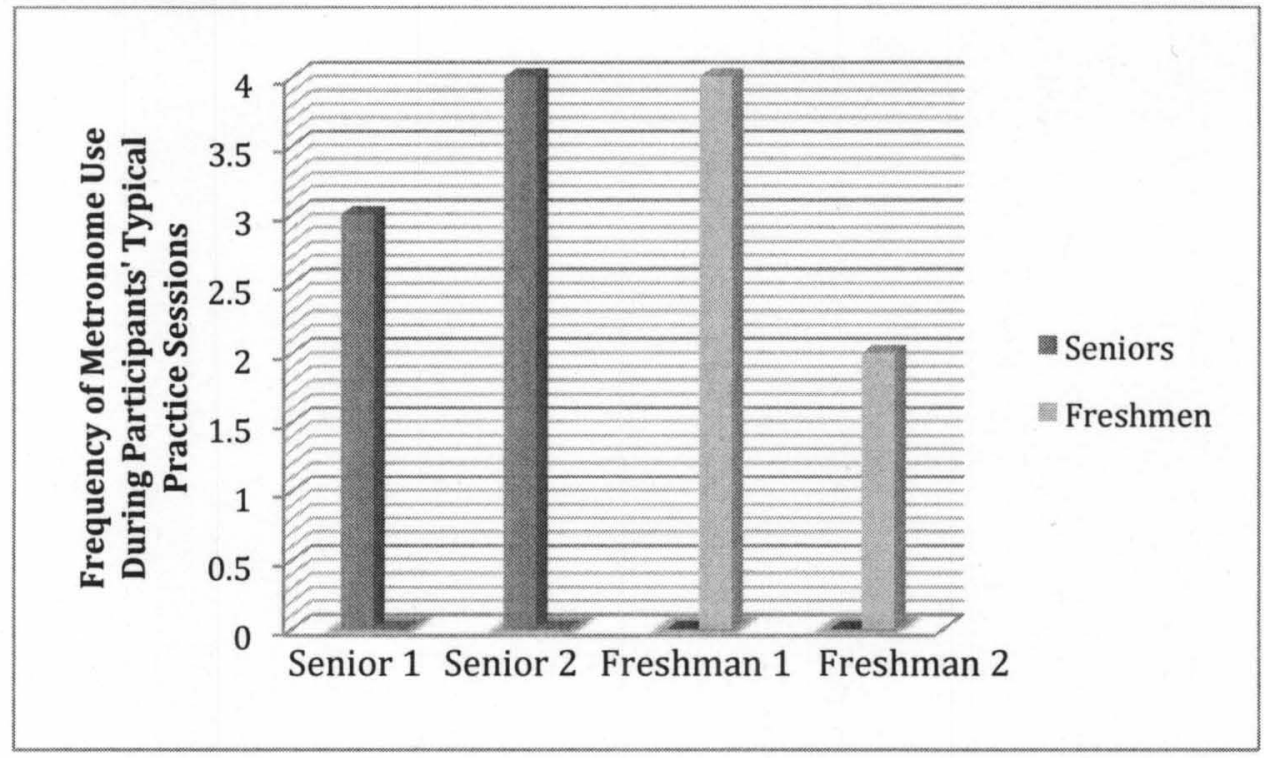


It can only be assumed that the participants were honest when answering the question regarding practice time in the week prior to the study. The survey answers to this question are illustrated in Figure 6. Regardless of reasons, it is clear that the seniors practiced considerably more during the week prior to the study.

Figure 6. Number of Reported Hours Participants Spent Practicing Last Week

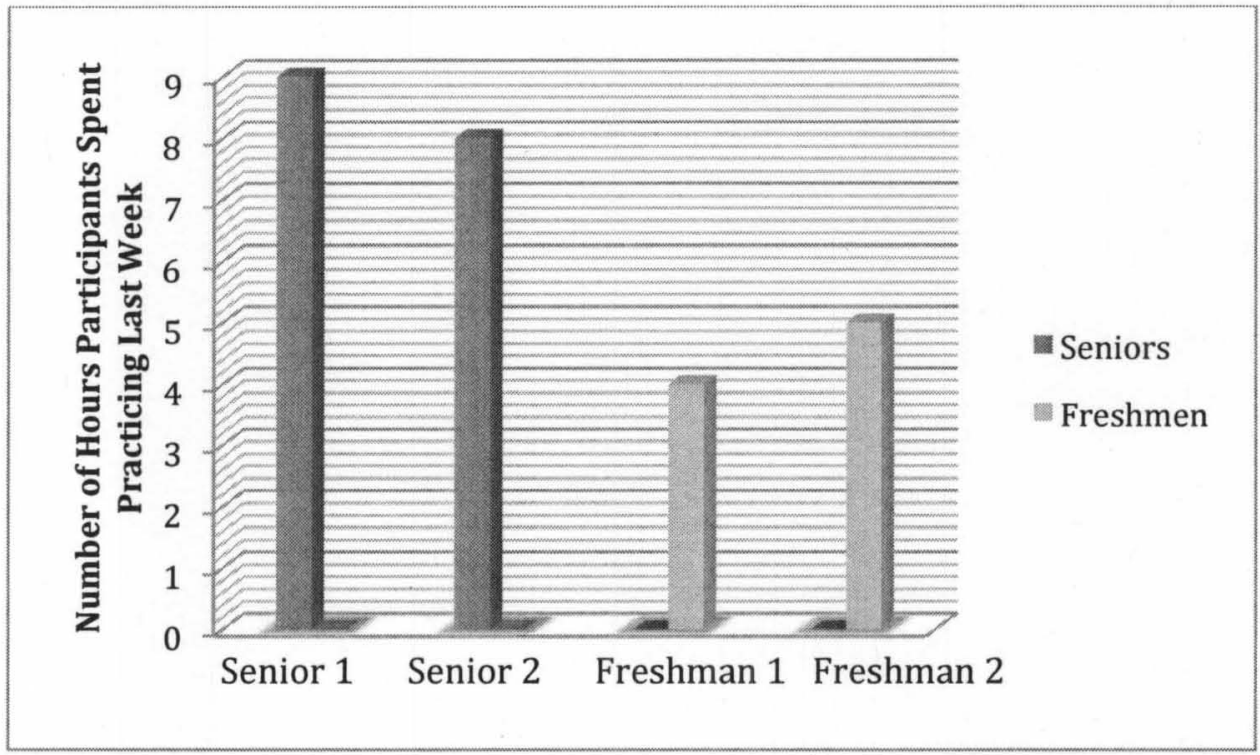


Table 1 illustrates other survey responses regarding warm up time, practice tools used and participants' ratings on the success of each session.

\section{Table 1.}

Other Survey Responses

\begin{tabular}{lcccc}
\hline & Senior 1 & Senior 2 & Freshman 1 & Freshman 2 \\
\hline Time Regularly & $16-30$ minutes & $10-15$ minutes & $16-30$ minutes & $1-15$ minutes \\
$\begin{array}{l}\text { Spent on Warm } \\
\text { Up }\end{array}$ & Tuner; Pencil & $\begin{array}{c}\text { Mouthpiece; } \\
\text { Piano }\end{array}$ & $\begin{array}{c}\text { Metronome; } \\
\text { Berp }^{1}\end{array}$ & NONE \\
$\begin{array}{l}\text { Tools Used } \\
\text { During Session }\end{array}$ & 4 & 3 & 3 & 5 \\
$\begin{array}{l}\text { Success of } \\
\text { Session 1 (1-5) }\end{array}$ & 4 & 3 & 2 & 4 \\
$\begin{array}{l}\text { Success of } \\
\text { Session 2 (1-5) }\end{array}$ & 4 & & & 4 \\
\hline
\end{tabular}

\footnotetext{
${ }^{1}$ A Berp is a device used by brass players to practice mouthpiece buzzing. The Berp attaches to the lead pipe of the instrument, and a player can choose to insert the mouthpiece into the Berp instead of into the lead pipe. Then the player can practice buzzing into the mouthpiece while holding the instrument in the standard playing position. The Berp reduces pressure on the embouchure while buzzing and also enables a player to practice fingerings at the same time.
} 


\section{Responses To The Post Practice Survey}

At the conclusion of the 15 minutes of practice during each session, participants were asked to describe their preparation and execution of the practice period. Complete versions of Survey A and Survey B are illustrated in the Appendix (Figures 11 and 12). Following are abridged versions of each question along with the participants' written responses.

\section{Senior Participant 1}

(Senior Participant 1) Participant's comments on survey during first session:

1. Warm up before first session:

"Yes, I warmed up this morning. I spent about 20 minutes warming up. I buzz on the Berp, sing, and play flow studies. Next I play long tones, and then I do 3 different types of lip slur exercises."

2. Approach to learning étude:

"I like to start at the beginning and work my way to the end when learning a new piece. If there were difficult spots, I would slow them down, take them down an octave, or repeat them over and over. Once I've repeated the tough spot correctly a few times, I will move on and continue learning the rest of the piece."

3. Tools or practice aids used:

- "Tuner: I tuned before I began the étude. I also glanced at the tuner during my practice, especially on long notes to get them in tune."

- "Pencil: I used it for accidentals."

4. Aspects that were most effective:

"Taking a phrase down an octave to get it in my ear. I feel that this helped once I took it back to its original range."

5. Aspects that were least effective:

"I usually tap my foot to the beat, but that wasn't as effective with this étude because of the rhythmic freedom."

6. If there were more time, the next steps would be:

"Connecting the piece together in longer phrases. I tend to make short, choppy phrases when learning a piece for the first time. I need to put the previous work together and focus on longer musical phrases." 
(Senior Participant 1) Participant's comments on survey during second session:

1. Warm up before second session:

"Yes, about 25 minutes was spent warming up. I played flow studies, long tones, buzzed on the mouthpiece, played three sets of lip slurs, and played expanding range arpeggios."

2. Approach to learning étude:

"I started at the beginning and worked my way through. I would stop at problem areas and work on fixing them. Often I would go back a measure and put the "problem area" into context. I played lines down an octave if I needed to hear it better and I slowed down my tempo to get correct notes and rhythms."

3. Tools or practice aids used:

- "Tuner: to make sure I was in tune in the beginning."

- "Pencil: to mark accidentals."

4. Aspects that were most effective:

"Slowing down the pulse in order to get correct notes or rhythms.

Sometimes I outlined the basic chord, leaving some notes out, and that helped a lot too."

5. Aspects that were least effective:

"I didn't use the tuner, so I have no clue if I was playing in tune, other than my tuning note, "G." This was probably because of the quickly moving notes in the étude."

6. If there were more time, the next steps would be:

"Continue learning the second half and then piecing it together to make bigger phrases.

(Senior Participant 1) Observations on the practice behaviors of this participant:

Senior 1 seemed to be very patient and methodical. During the two practice sessions, this participant rarely played more than four measures at a time and instead focused on playing each note and rhythm correctly every time. She began by tuning and playing a few notes while watching the tuner. Once Senior 1 began working on the piece, she preferred to play fragments and used a "chunking" technique to isolate difficult sections of pitches and rhythms. Senior 1 played everything at a slower tempo until it 
was accomplished correctly, and then increased the tempo closer to what was marked. This participant played the each étude slower than any of the other participants, but had the most accurate intonation and the most careful rhythms, dynamics, and style. This participant chose to solve the dilemma of the out-of-range low $\mathrm{C}$ (mentioned during discussion of études in METHOD section) in the second étude by playing it in the octave higher. 


\section{Senior Participant 2:}

(Senior Participant 2) Participant's comments on survey during first session:

1. Warm up before first session:

"I did warm up today and before this session. This morning I played a 45minute warm up that I play each weekday. Before this session I warmed up for about five minutes."

2. Approach to learning étude:

"For this étude I first wanted to understand aurally the harmonic structure that I was outlining. I tried to figure out the different roots I was playing around. This drastically helps my ear understand what I'm playing.

Beyond I essentially try to just sing exactly what I'm hearing through the trumpet, addressing musical and trumpet issues as they come up. My focus is always aural first when practicing an étude though."

3. Tools or practice aids used:

"Today all I used was my mouthpiece and the piano. I used them to get my ears working with my air on a better level."

4. Aspects that were most effective:

"Playing some of the chords and singing/buzzing pitches was most beneficial for me. This is generally my go-to practice technique for lyrical playing like this."

5. Aspects that were least effective:

"I briefly tried some deep breathing to help open me up but I stayed relatively tense throughout the practice."

6. If there were more time, the next steps would be:

"My next step would be ironing out the rhythms and deciding exactly what to do in terms of shaping phrases."

\section{(Senior Participant 2) Participant's comments on survey during second session:}

1. Warm up before second session:

"I warmed up very briefly before the session. I devoted almost no time to warming up today."

2. Approach to learning étude:

"I broke it into sections and attempted to play through them, singing/buzzing/air playing the parts I was having trouble with." 
3. Tools or practice aids used:

- "Mouthpiece: buzzing/ear"

- "Visualizer: air flow/phrasing"

- "Piano: ear/pitch reference"

4. Aspects that were most effective:

"Singing helped the most. I was very tense and playing like I'm singing always helps."

5. Aspects that were least effective:

"Buzzing; my chops were not ready to support what I needed."

6. If there were more time, the next steps would be:

"Outlining the chords, singing it more accurately, and speeding it up slowly."

(Senior Participant 2) Observations on the practice behaviors of this participant:

This participant spent a great portion of the allotted practice time singing, using the piano, buzzing on his mouthpiece, and silently fingering through his music. He was the only participant to silently finger through the entire piece before playing a single note. Once he began playing after his first silent reading, he played through the entire piece once and then went back to isolate spots for improvement. During each session, he went back and forth between his trumpet, the piano, his mouthpiece, and singing. He seemed to be very aurally focused. At the second session though, it is significant to note that the participant was in a hurry and didn't seem to be as on-task as he was during the first session. He didn't have more than a few minutes to warm up before the session, so his playing may not have been as productive as it could have been otherwise. Still, his methods of concentrating on pitch and aural issues while using the piano, mouthpiece and singing as tools remained consistent. Also, this participant's solution to the out-of-range low $\mathrm{C}$ in the second étude was to play it in the octave higher. 


\section{Freshman Participant 1:}

(Freshman Participant 1) Participant's comments on survey during first session:

1. Warm up before first session:

"Yes, I did warm up today. It lasted about 30 minutes and consisted of: Long tones starting at $G$ in the staff and expanding chromatically to the $G$ below and above the staff; slurs in several patterns; one minute tonguing sixteenths at 90 BPM; Clarke Study \#2 (all of them); Concone lyrical study"

2. Approach to learning étude:

"I tried to think of the fastest tempo I could successfully play the étude's hardest part. Then I cut that back by ten and did a slow run attempting to hit all the notes correctly. If I missed a note I made sure to stop and fix it, then move on. After that I ran a few of the tougher spots, then moved on to just blowing through it without the trumpet, sometimes using the berp."

3. Tools or practice aids used:

- "Metronome-establish a tempo"

- "Berp — center the pitch on a few awkward points"

4. Aspects that were most effective:

"Slow practice for me is always the best practice and the practice I feel also that is the most effective."

5. Aspects that were least effective:

"The parts where I got ahead of myself and took an unplayable tempo that just engrains wrong pitches."

6. If there were more time, the next steps would be:

"Try and find a recording and next I would center all of the pitches with the berp, then sing and conduct."

\section{(Freshman Participant 1) Participant's comments on survey during second session:}

1. Warm up before second session:

"I didn't warm up before this étude."

2. Approach to learning étude:

"I wanted to play through it slowly to engrain it in my fingers and then isolate some tougher passages."

3. Tools or practice aids used: 
"I didn't use any."

4. Aspects that were most effective:

"Taking it in half time let me really work on pitch."

5. Aspects that were least effective:

"The stopping and starting points."

6. If there were more time, the next steps would be:

"Using a tuner and metronome."

\section{(Freshman Participant 1) Observations on the practice behaviors of this participant:}

During casual conversation with the participant it was learned that he began playing trumpet in sixth grade, and began taking regular lessons in eighth grade. The length of time he has been taking lessons is on par with the length of time the seniors have taken lessons, and it could be related that he also rated lessons at a helpfulness level of 5 (the maximum rating). This participant was the only one who used a metronome during either of his practice sessions. He did not use it consistently, but instead to establish a baseline for tempo. He also used his Berp when attaining accurate pitches in difficult sections became challenging to him. Notably, this participant made a point to not repeat anything incorrectly, and changed his tactics anytime he made a mistake. He did not make the same mistake multiple times because of this. He used a "chunking" technique to piece together sections of the étude. He first isolated difficult patterns and worked on them before combining them into larger phrases. He did not, however, achieve a complete run of the étude. He instead focused on perfecting pitches, rhythms, and flow of phrases. Another item to note is the fact that this participant did choose to play the out-of-range low $\mathrm{C}$ in the second étude in an octave higher, as did Seniors 1 and 2. 


\section{Freshman Participant 2:}

\section{(Freshman Participant 2) Participant's comments on survey during first session:}

1. Warm up before first session:

"I did warm up before this session, but it wasn't extensive. I view the warm up less as an elongated process but as simply the time it takes for the lip membrane to become flexible enough to produce a desirable tone; therefore, a few long tones and range expanding exercises are what I use as I prepare to play."

2. Approach to learning étude:

"This was, for me, a simple étude to learn. I first noticed that there were no bar lines. To learn the notes, I simply practiced through repetition (I did practice an arpeggiation at one point). Given another 15 minutes, I feel this étude would be performance-ready. My only point of contention regards the lack of bar lines: Should they be perceived as a license for expression and rubato? Or should I rather stick strictly to the composer's note values? To find a solution, I would either find a recording or consult my professor."

3. Tools or practice aids used:

"No practice aids or tools."

4. Aspects that were most effective:

"Repetition was essentially the only specific method I used. The difficulty of the étude did not demand anything else."

5. Aspects that were least effective:

"I cannot describe a specific technique as I feel as if my learning methods were not flawed. To answer this question with more certainty, an étude of greater difficulty would be recommended."

6. If there were more time, the next steps would be:

"I would run the étude in its entirety to perfect the flow of the phrases."

(Freshman Participant 2) Participant's comments on survey during second session:

1. Warm up before second session:

"I did warm up today, but very briefly. I simply did some lyrical lines and things that would take me around the range of the horn. Once again, I believe that the warm up is only what should be performed to get the lip membrane to vibrate vibrantly and fully, nothing more."

2. Approach to learning étude: 
"I first noticed that this étude was slightly more difficult than the last. I started my practicing by doing a complete run-through in which I identified three or four trouble sports. I then simply rehearsed these at a slower tempo until my technical facility was sufficient to perform them (Note: I did not finish learning the étude)."

3. Tools or practice aids used:

"I didn't use any practice tools."

4. Aspects that were most effective:

"Playing this étude at a slower tempo, and subsequently raising the tempo, is the only technique I would need to complete this étude (there is a low $\mathrm{C}$, a note not within the normal range. I simply left it out as developing that pitch would take weeks of practice). The slow tempo technique (if you can call it that) was successful in my approach."

5. Aspects that were least effective:

"I feel like I only used one technique (slow tempo) and it worked for the piece. However, if I lacked the technical facility to do the doubletonguing lick on the second to last line, I could have used some doubletonguing exercises to get that under control. It seemed to be fine today."

6. If there were more time, the next steps would be:

"I would continue to work on the hard, fast spots. Another 30 minutes would be sufficient to prepare this piece for performance.

\section{(Freshman Participant 2) Observations on the practice behaviors of this participant:}

This participant seemed to be less thorough than the others in regards to extensive study of the piece. He played more complete phrases than small fragments. This participant played through the entire piece during the first and second practice sessions before rehearsing any sections, and was the only participant to do so. He played many correct notes and rhythms during the first session, but did not seem to be focused on making "musical" phrases with items such as dynamics, tempo fluctuations, and style differentiations. This player placed emphasis on playing correct pitches and rhythms. During the second session Freshman 2 also played more notes correctly than incorrectly, but because the second étude was longer and more complex, he also missed quite a few 
pitches without stopping or returning to fix them. In general, he learned the études at a faster pace than the other participants and seemed to find both études relatively easy (as demonstrated by both his playing and his comments on the survey). It should be noted that his practice methods did not include any advanced techniques other than small instances of repetition of longer phrases and slight slowing of tempos during difficult passages.

In his second survey, Freshman 2 mentioned that slowing the tempo was the only technique he used. He played the entire étude before going back to repeat or adjust anything, but he did then use some repetition by repeating a few select phrases. Each phrase he selected again was repeated once. In his survey he also noted that the piece would be performance-ready in another 30 minutes, even though he didn't pay any attention to intonation, centering of pitches, or phrasing. He missed quite a few pitches and his tempo and rhythms were not completely accurate. He did not use a metronome, tuner, piano, or any other tool to work on these issues, so he may not have been aware of the issues.

As noted earlier in discussion of the études, this second piece by Belloli was chosen despite the inclusion of one note (a low "C") that is not in the standard range of the trumpet. I was interested in seeing the players' reactions to this note and discovering how they would handle the situation—would they substitute another note or would they leave it out entirely? This player chose to not play the note, where the others all chose to play it in the higher octave. 


\section{DISCUSSION}

The purpose of this qualitative study was to investigate how four college music students—-two seniors and two freshmen - practiced as they prepared an étude.

Based on the participants' survey answers, as well as the disparities in practice methods used and positive relationships with age and experience, it can be concluded that amount of teacher influence or length of time taking private lessons can be significant factors in the development of practice behaviors, and most particularly in strategies of self-regulation and perception of areas that need improvement. The three students who reported longer periods of time taking private lessons (Seniors 1 and 2, and Freshman 1) were the most patient and methodical with learning pitches and rhythms correctly, and with developing phrases within the études.

A few specific practice methods were observed during the practice sessions of the participants. All participants used repetition. Other methods used were "chunking," singing, buzzing on the mouthpiece, matching pitch from the piano, and slowing the tempo down to a more manageable one. There were no apparent trends between the freshmen and seniors on which students used more techniques, although from my observations of Senior 1 and Freshman 1, these two participants seemed to have more effective practice sessions because they had the most pitch and rhythmic accuracy in their playing, and because they also had the fewest errors in pitch and rhythm.

Freshman 2, who has been taking lessons for the least amount of time (1-3 years) was the only participant who did not rate the helpfulness of lessons at a level of 5 
(Extremely Helpful). This was also the only participant who did not use any practice tools or implements, and he was the only participant who only used repetition. Also, this participant's answers on the survey indicate that he does less warming up than the other participants. His comments regarding his warm up routine suggest that he does not view the warm up as a central part of the practice routine. While he used fewer techniques during his practice sessions, he was the only participant to rate his sessions at a level of 5 (Extremely Productive).

During casual discussion with Freshman 2 it was discovered that he started trumpet in the sixth grade and only took one year of lessons as a ninth grader in high school. From this information it is clear that he has the least amount of exposure to a one-on-one teaching setting. This lack of outside influence on his practice procedures may be related to his practice routine.

There may be a connection between private lessons and practice routines. When comparing the practice behaviors and survey answers of Freshman 2 to those of the other three participants, one might make the connection between his shorter private lesson experience and the way he practiced and viewed his practice sessions. Freshman 2 only used repetition and no tools, and has only taken private lessons for two years. The other three participants used more techniques and tools, and have taken private lessons at least six years each. These differences may also affect the level of focus toward musicality versus surface aspects such as rhythm and pitch.

The seniors indicated on the survey that they practiced more hours the previous week than did the freshmen. Although Freshman 1 indicated he has been taking lessons for approximately the same number of years as one of the seniors, perhaps the length of 
time spent taking lessons has little impact on the emphasis a student places on practice time. Or perhaps the seniors are preparing for senior recitals and are therefore practicing more often? This discrepancy in practice time is a question that should be investigated further before conclusions can be made.

Given the observations of participants' practice sessions and answers participants gave on surveys, the following themes emerged:

1. Practice routines vary based on the techniques a student uses in order to hone a skill or rehearse a piece of music. The strategies used by instrumental students in a practice seem to be highly impacted by exposure to private lessons, and it seems that the longer a student takes private lessons, the more efficient and productive their practice sessions can be. While one freshman in this study played through a piece with minimal rehearsal, the other participants were much more methodical.

2. Use of tools: Despite the availability of a mirror, a piano, and the option of using a metronome, tuner, Berp, mouthpiece, breathing apparatus or some other device, students don't always take advantage of the tools accessible to them. Even though these students are probably aware of the potential helpfulness of some of these tools, they rarely chose to use one of them consistently (throughout the entire practice session). There was a trend in the three students who did use some tools, however. Each of these students had a longer experience with private trumpet lessons than did the fourth student.

3. "Chunking," or the isolating of difficult passages into smaller and more manageable pieces, was the most common technique used by Seniors 1 and 2 as 
well as Freshman 1. This technique enabled the students to focus on playing a difficult passage correctly until it was mastered.

In conclusion, it seems that private lessons are the common factor in this study for practice room success. It is critical that teachers instruct students on productive practice behaviors, whether they are demonstrating by example or providing goals and specific techniques with which the student should practice. The results of this study indicate that age is not as important to success as methods used, attitude toward improvement and influence of a mentor on how to practice efficiently. The three students with the most successful practice sessions (i.e., most improvement and fewest errors) all indicated that they have been taking lessons for at least six years, which is longer than the third participant has been taking lessons. The methods used most successfully by students in this study were repetition, chunking, slowing the tempo down, and matching pitch from the piano or mouthpiece buzz and from singing. With this connection, teachers may be able to direct their focus toward coaching these techniques. More research could determine further aspects of private lessons that provide the most opportunities for success. 


\section{APPLICATIONS FOR FUTURE RESEARCH}

This study introduced many opportunities for further study pertaining to instrumental practice and the effects of private lessons. There is a great deal of need for more research into what actions teachers and musicians can take in order to ensure success. The following are suggested ideas for continuing this research

If the study were continued or repeated, using a larger sample of participants from a wider population (i.e., pull a greater number of participants from more than one school) would be recommended. Also, it might be helpful to use more age groups or a wider range of ages for participants. By using a larger or more diverse population, the findings of the study could become more valuable to musicians and educators, as they could use the knowledge to improve their existing methods.

Making practice sessions longer would provide more opportunities for observations and data collection, as well as give participants more opportunities to describe their methods. It would also be useful to schedule additional practice sessions for each participant. Having more data to study would also help to provide more ideas for expanding this research.

Rating videos for on-task and off-task behaviors would provide additional data to be analyzed, and may provide further insight. Asking a third party to view the videos and rate the practice sessions on levels of success or improvement would also be a beneficial and objective way to provide more data. Watching the videos to tally mistakes (pitch, rhythm, etc.) would provide some quantitative data and enable significance to be found, if 
applicable. Watching the videos to tally learning techniques used, such as repetition, would also provide quantitative data. These ideas would aid in expanding comparisons between the participants.

Making the surveys more intensive and specific so as to obtain more details from participants would help make answers more consistent, which would make them simpler to compare. Obtaining more guided and detailed answers through an interview process instead of a survey would also help with this. Adding questions to the survey would enable the researcher to look for other factors besides practice behaviors and playing experience.

Using the same étude for multiple sessions with each participant might yield more information on long term practice habits, as would spreading sessions out over months to determine improvement over a longer period of time. Allotting time during the practice sessions for warm up exercises would enable the researcher to directly analyze participants' warm up routine, instead of asking about it in the survey. Also, instructing participants not to warm up prior to the session, or limiting their warm up to a certain amount of time or specific exercises may create an equal starting point for each participant.

Asking participants to demonstrate specific behaviors or focus on precise elements, and comparing their interpretations of those behaviors (i.e., "focus on playing correct rhythms," or "tune the arpeggio") would direct the study for more specific comparisons. This would allow the researcher to focus on how students apply technique, and to study how participants uniquely apply methods such as repetition to a specific 
task. Being able to study the same techniques used by all participants would also provide more data for comparison. 


\section{REFERENCES}

Austin, J. R., \& Berg, M. H. (2006). Exploring music practice among sixth-grade band and orchestra students. Psychology of Music, 34(4), 535-558.

Bandura, A. (1986). The explanatory and predictive scope of self-efficacy theory. Journal of Social and Clinical Psychology, 4(3), 359-373.

Barber, B. (1991). "Traditional \& Suzuki teaching: a comparison". American String Teacher.

Beheshti, S. (2009). Improving studio music teaching through understanding learning styles. International Journal of Music Education, 27(2), 107-115.

Bergee, M. J. (2005) An exploratory comparison of novice, intermediate, and expert orchestral conductors. International Journal of Music Education, (23), 23-36.

Brathwaite, A. (1988) Suzuki training: musical growth or hindrance? Music Educators Journal, 75(2), 42-45.

Brendell, J. K. (1996). Time use, rehearsal activity, and student off-task behavior during the initial minutes of high school choral rehearsals. Journal of Research in Music Education, 44(1), 6-14.

Bronfman, J. (2009). Choral music in the junior high/middle school - do it again: repetition in the middle school choral rehearsal. The Choral Journal, 49(9), 81.

Bronfman, J. (2009). Choral music in the junior high/middle school - repeating with variety: implementing motor learning theory in the choral rehearsal. The Choral Journal, 50(1), 61.

Butler, D. L. (2002). Individualizing instruction in self-regulated learning. Theory into Practice, 41(2), 81-92.

Byo, J. L. (2004). Teaching problem solving in practice. Music Educators Journal, 91(2), 35 .

Byo, J., \& Austin, K. (1994). Comparison of expert and novice conductors: An approach to the analysis of nonverbal behaviors. Journal of Band Research, 30(1), 11-34. 
Byo, J., \& Cassidy, J. (2008). An exploratory study of time use in the practice of music majors. Update: Applications of Research in Music Education, 27(1), 33-40.

Christensen, S. (2010). Practicing strategically: the difference between knowledge and action in two eighth-grade students' independent instrumental practice. Update: Applications of Research in Music Education, 29(1), 22-32.

Colprit, E. J. (2000). Observation and analysis of Suzuki string teaching. Journal of Research in Music Education, 48(3), 206-221.

Cope, P. (2005). Adult learning in traditional music. British Journal of Music Education, 22(2), 125-140.

Cox, D. K. (1985). Suzuki, chorally speaking. Music Educators Journal, 7l(9), 43-45.

Cox, J. (1989). Rehearsal organizational structures used by successful high school choral directors. Journal of Research in Music Education, 37(3), 201-218.

Dorfman, J. (2010). The relationships between time usage during instrumental lessons and preservice teachers' self-evaluations. Journal of Music Teacher Education, 19(2), 89-99.

Duke, R., Simmons, A., \& Cash, C. (2009). It's not how much; it's how. Journal of Research in Music Education, 56(4), 310-321.

Elliot, D. J. (1995). Music matters. New York: Oxford University Press.

Fuelberth, R. J. (2003). The effect of left hand conducting gesture on inappropriate vocal tension in individual singers. Bulletin of the Council for Research in Music Education, 157, 62-70.

Garson, A. (1970). Learning with Suzuki: seven questions answered. Music Educators Journal, 56(6), 64-66; 153-154.

Goolsby, T.W. (1999). A comparison of expert and novice music teachers' preparing identical band compositions: an operational replication. Journal of Research in Music Education, 47(2), 174-187.

Gordon, E. (1992). Advanced measures of music audiation. Chicago, IL: G.I.A. Publications.

Henley, P. T. (2001). Effects of modeling and tempo patterns as practice techniques on the performance of high school instrumentalists. Journal of Research in Music Education, 49(2), 169-180. 
Hewitt, M. P. (2011). The impact of self-evaluation instruction on student self-evaluation, music performance, and self-evaluation accuracy. Journal of Research in Music Education, 59(1), 6-20.

Hyllegard, R., \& Bories, T. L. (2008). Deliberate practice theory: relevance, effort, and inherent enjoyment of music practice. Perceptual and Motor Skills, 107(2), 43948.

Hyllegard, R., \& Bories, T. L. (2009). Deliberate practice theory: perceived relevance, effort, and inherent enjoyment of music practice: study II. Perceptual and Motor Skills, 109(2), 431-40.

Jørgensen, H. (2002). Instrumental performance expertise and amount of practice among instrumental students in a conservatoire. Music Education Research, 4(1), 105119.

Kostka, M. J. (2004). Teach them how to practice. Music Educators Journal, 90(5), 23.

Leon-Guerrero, A. (2008). Self-regulation strategies used by student musicians during music practice. Music Education Research, 10(1), 91-106.

Madsen, Clifford K. (2004). "A 30-year follow-up study of actual applied music practice versus estimated practice." Journal of Research in Music Education. 52(1), 77.

McPherson, G. E., \& McCormick, J. (1999). Motivational and self-regulated learning components of musical practice. Bulletin of the Council for Research in Music Education, 141(141), 98-102.

Miksza, P. (2007). Effective practice. Journal of Research in Music Education, 55(4), 359-375.

Miksza, P. (2009). "Relationships among impulsivity, achievement goal motivation, and the music practice of high school wind players." Bulletin-Council for Research in Music Education. (180), 9-28.

Miksza, P. (2011). Relationships among achievement goal motivation, impulsivity, and the music practice of collegiate brass and woodwind players. Psychology of Music, 39(1), 50-67.

Miksza, P. (2012). The development of a measure of self-regulated practice behavior for beginning and intermediate instrumental music students. Journal of Research in Music Education, 59(4), 321-338.

Myers, I. B. \& McCaulley, M. H. (1985). Manual: A Guide to the Development and Use of the Myers-Briggs Type Indicator (2nd ed.). Palo Alto, CA: Consulting Psychologists Press. 
Nielsen, S. G. (2001). Self-regulating learning strategies in instrumental music practice. Music Education Research, 3(2), 155-167.

Nielsen, S. G. (1999). Learning strategies in instrumental music practice. British Journal of Music Education, 16(3), 275-291.

Nielsen, S. G. (2004). Strategies and self-efficacy beliefs in instrumental and vocal individual practice: a study of students in higher music education. Psychology of Music, 32(4), 418-431.

Nielsen, S. G. (2008). Achievement goals, learning strategies and instrumental performance. Music Education Research, 10(2), 235-247.

Oare, S. (2011). Practice education: teaching instrumentalists to practice effectively. Music Educators Journal, 97(3), 41-47.

Pedrick, D. (1998). Effective practice makes successful performance. Music Educators Journal, (85), 2.

Peterson, B. (2001). Three ways to practice more creatively. Music Educators Journal, $88(3), 46-71$.

Pike P.D., \& Carter R. (2010). Employing cognitive chunking techniques to enhance sight-reading performance of undergraduate group-piano students. International Journal of Music Education. 28, 231-246.

Price, H. E. (1983). The effect of conductor academic task presentation, conductor reinforcement, and ensemble practice on performers' musical achievement, attentiveness, and attitude. Journal of Research in Music Education, 31(4), 245 257.

Raven, J., Raven, J. C., \& Court, J. H. (1998). Manual for Raven's progressive matrices and vocabulary scales. Oxford: Oxford Psychologists.

Rohwer, D., \& Polk, J. (2006). Practice behaviors of eighth-grade instrumental musicians. Journal of Research in Music Education, 54(4), 350-362.

Ruthsatz, J., Detterman, D., Griscom, W. S., \& Cirullo, B. A. (2008). Becoming an expert in the musical domain: it takes more than just practice. Intelligence, 36(4), 330338.

Schatt, M. D. (2011). High school instrumental music students' attitudes and beliefs regarding practice: an application of attribution theory. Update: Applications of Research in Music Education, 29(2), 29-40. 
Shehan, P. K. (1986). Major approaches to music education: an account of method. Music Educators Journal, 72(6), 26-31.

Skadsem, J. A. (1997). Effect of conductor verbalization, dynamic markings, conductor gesture, and choir dynamic level on singers' dynamic responses. Journal of Research in Music Education, 45(4), 509-520.

Smith, B. (2005). Goal orientation, implicit theory of ability, and collegiate instrumental music practice. Psychology of Music, 33(1), 36-57.

Stambaugh, L. (2011). When repetition isn't the best practice strategy: effects of blocked and random practice schedules. Journal of Research in Music Education, 58(4), 368-383.

Stambaugh, L., \& Demorest, S. (2010). Effects of practice schedule on wind instrument performance: a preliminary application of a motor learning principle. Update: Applications of Research in Music Education, 28(2), 20-28.

Symonds, P. M., \& Chase, D. H. (1992). Reprint of "Practice vs. Motivation". Journal of Educational Psychology, 84(3), 282-89.

Tatton, T. (1997). Effective practice techniques. American String Teacher, 47(2), 57-61.

Turpin, D. (1986). Kodály, Dalcroze, Orff, and Suzuki: application in the secondary schools. Music Educators Journal, 72(6), 56-59.

Vaughan, V. (2002). Music analysis in the practice room. British Journal of Music Education, 19(3), 255-268.

Yarbrough, C. and Price, H. E. (1981). Prediction of performer attentiveness based on rehearsal activity and teacher behavior. Journal of Research in Music Education, 29(3), 209-217.

Zhukov, K. (2007). Student learning styles in advanced instrumental music lessons. Music Education Research, 9(1), 111-127. 


\section{APPENDIX}

\section{Figure 7. Initial contact email}

Hello! My name is Jennifer Pope, and I am a Graduate Student at the University of Louisville. I am currently working on a project for my thesis, and I would like to invite you to participate in my study! I promise it will be simple, and it won't take much of your time.

Here is some basic information on what this study will entail:

- ONE initial meeting to go over details and any questions you may have. ( $\sim 5$ minutes)

- TWO subsequent meetings where you will bring your trumpet and be given an étude to work up to the best of your ability. At the end of these sessions, you will take a brief survey about how you approached this task. ( $\sim 25$ total minutes for each session)

And that is all! I hope you will choose to help me out and participate in my study...please let me know as soon as possible!

CONTACT INFORMATION:

Jennifer Pope

Primary Contact

(859) 333-8464

jennifer.pope@louisville.edu
Dr. Robert Amchin

Principal Investigator

(502) 852-0536

raamch01@louisville.edu 


\section{Figure 8. Consent Form}

$$
\text { For IRB Approval Stamp }
$$

\section{Subject Informed Consent Document}

\section{Self-Regulated Practice: A Comparison Between Senior and Freshman Trumpet Students}

IRB assigned number:

Investigator(s) name \& address: Dr. Robert Amchin, 2301 S. Third St., Louisville, KY 40292

Site(s) where study is to be conducted: University of Louisville School of Music

Phone number for subjects to call for questions: Jennifer Pope, (859) 333-8464

\section{Introduction and Background Information}

You are invited to participate in a research study. The study is being conducted by Dr. Robert Amchin and Jennifer Pope, graduate student at the University of Louisville. The study is sponsored by the University of Louisville, Department of Music. The study will take place at The University of Louisville School of Music . Four subjects will be invited to participate.

\section{Purpose}

The purpose of this study is to investigate how four college music students-two seniors and two freshmen-practice as they prepare an étude.

\section{Procedures}

In this study, you will be asked to prepare two different études using your own approaches to learning a piece of music. This will be videotaped. After your work on the étude, you will be asked to complete a survey on your method of learning the music.

\section{Potential Risks}

There are no foreseen risks to a participant in this study. There may be unforeseen risks.

\section{Benefits}

The possible benefits of this study include learning new études and reflecting on how you approach a new piece of music. The information collected may not benefit you directly. The information learned in this study may be helpful to others.

\section{Compensation}




\section{Figure 8. Consent Form (continued)}

You will not be compensated for your time, inconvenience, or expenses for your participation in this study.

\section{Confidentiality}

Total privacy cannot be guaranteed. Your privacy will be protected to the extent permitted by law. If the results from this study are published, your name will not be made public. While unlikely, the following may look at the study records:

The University of Louisville Institutional Review Board and Human Subjects Protection Program Office.

All data collected from this study will be stored in the researcher's locked office and kept on a password-protected computer.

\section{Voluntary Participation}

Taking part in this study is voluntary. You may choose not to take part at all. If you decide to be in this study you may stop taking part at any time. If you decide not to be in this study or if you stop taking part at any time, you will not lose any benefits for which you may qualify.

\section{Research Subject's Rights, Questions, Concerns, and Complaints}

If you have any concerns or complaints about the study or the study staff, you have three options.

You may contact the principal investigator at (502) 852-0536.

If you have any questions about your rights as a study subject, questions, concerns or complaints, you may call the Human Subjects Protection Program Office (HSPPO) (502) 852-5188. You may discuss any questions about your rights as a subject, in secret, with a member of the Institutional Review Board (IRB) or the HSPPO staff. The IRB is an independent committee composed of members of the University community, staff of the institutions, as well as lay members of the community not connected with these institutions. The IRB has reviewed this study.

If you want to speak to a person outside the University, you may call 1-877-852-1167. You will be given the chance to talk about any questions, concerns or complaints in secret. This is a 24-hour hot line answered by people who do not work at the University of Louisville.

This paper tells you what will happen during the study if you choose to take part. Your signature means that this study has been discussed with you, that your questions have been answered, and that you will take part in the study. This informed consent document is not a contract. You are not giving up any legal rights by signing this informed consent document. You will be given a signed copy of this paper to keep for your records. 


\section{Figure 8. Consent Form (continued)}

Signature of Subject/Legal Representative

Signature of Person Explaining the Consent Form (if other than the Investigator)

Signature of Investigator
Date Signed

Date Signed

Date Signed

\section{LIST OF INVESTIGATORS PHONE NUMBERS}

Dr. Robert Amchin, supervisor $\quad$ (502) 852-0536

Jennifer Pope

(859) 333-8464

For IRB Approval Stamp 
Figure 9. Étude 1: Gallay Unmeasured Prélude No. 21 for Horn

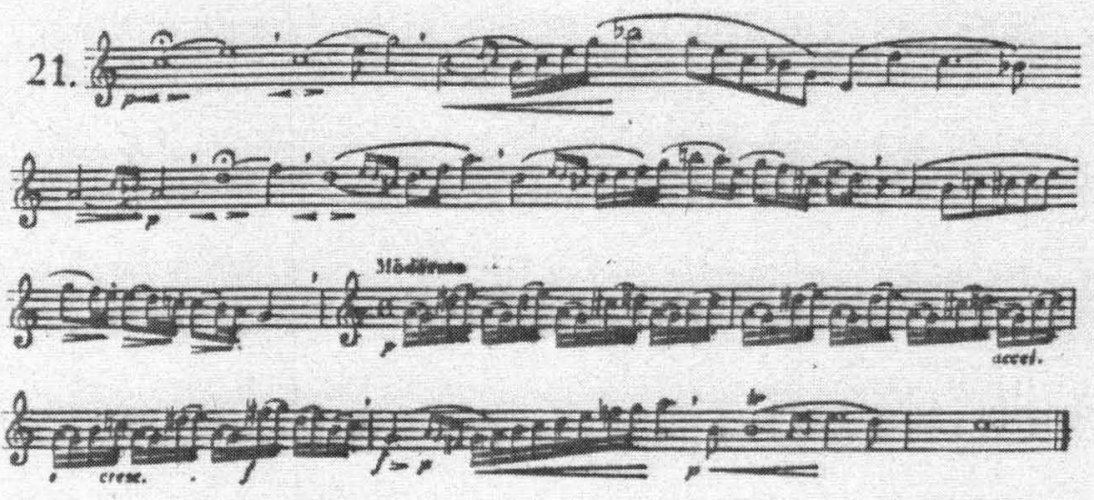


Figure 10. Étude 2: Belloli Study No. 1 for Horn

EIGHT STUDIES

for Horn

Reriled aY E. GUMBERT

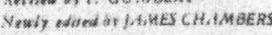

ACOSTINO BELLOLI

Yo. 1. Analante espressive

(4)

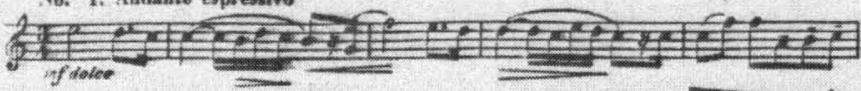

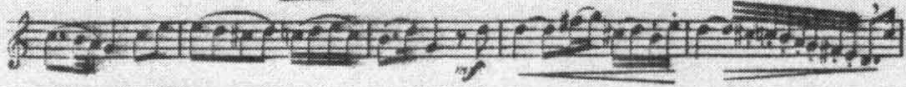

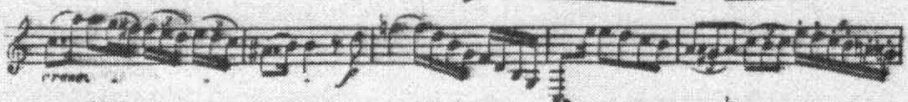

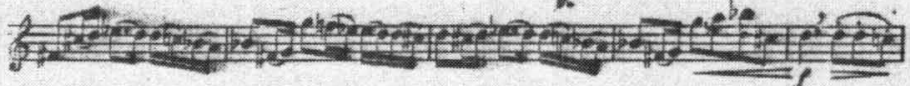

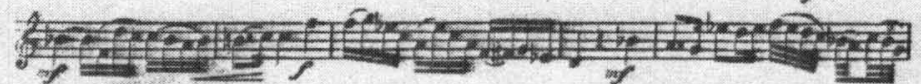

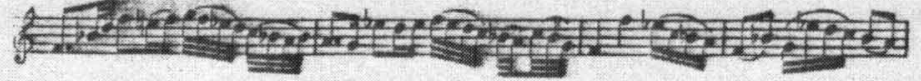

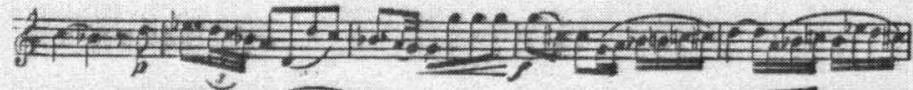

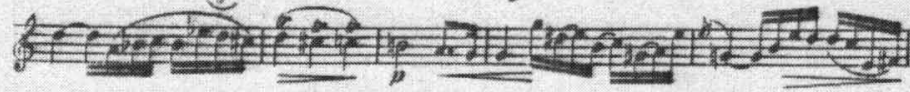

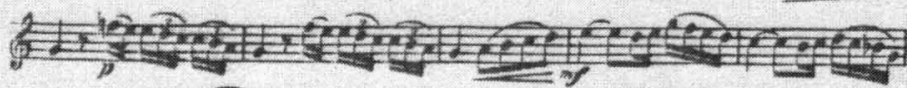

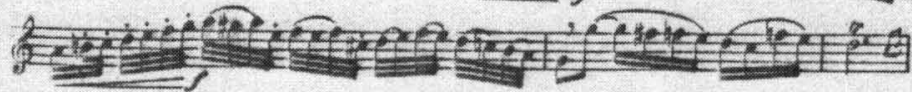

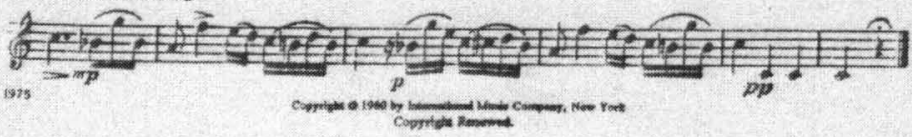




\section{Figure 11. Survey A}

Please fill out the following survey to the best of your ability, answering each prompt. You may be as concise or detailed as you deem necessary, but please provide any information you feel is relevant to the questions asked. You are not expected to fill the entire page, but if you need more space simply continue on the back of the page.

$\begin{array}{lll}\text { Circle your grade level: } & \text { SENIOR } & \text { FRESHMAN }\end{array}$

List your age in years:

How many years have you been playing trumpet?

How many years have you been taking trumpet lessons?

On a scale of $1-5$, how much have your trumpet lessons helped you in your practice routine? Circle your answer.

$\begin{array}{lllllll}\text { Not at all } & 1 & 2 & 3 & 4 & 5 & \text { A lot }\end{array}$

On a scale of 1-5, how often do you use a metronome in your practice sessions?

Never

$1 \quad \begin{array}{cccc}\text { Sometimes } & \text { All the time }\end{array}$

How much time do you typically spend "warming up" before you begin practicing a piece of music? Choose one option.

I don't warm up before practicing a piece of music

1-15 minutes of warm ups (e.g., scales and long tones)

16-30 minutes

$31-45$ minutes

46-60 minutes

More than 60 minutes of warm up

Did you warm up before this session? How much time did you devote to warming up today? 


\section{Figure 11. Survey A (continued)}

In simple terms, please describe your approach to learning this étude. Explain your thought processes, beginning with your first glance at the music. If you like, you may list your steps to learning this étude, and any specific techniques or methods you used during this session.

List any tools or practice aids you used today and explain why/how you used them.

In your opinion, what aspect(s) of your practice session today were MOST effective when learning this piece of music? Please describe at least one technique you used today that you felt was successful.

In your opinion, what aspect(s) of your practice session today were LEAST effective? Please describe at least one technique you used today that didn't work as well as you had hoped.

On a scale of $1-5$, how productive would you rate this practice session? Circle your answer.

$\begin{array}{llllllll}\text { Not productive at all } & 1 & 2 & 3 & 4 & 5 & \text { Extremely }\end{array}$ productive

If you had had more time to work on this étude, what would be your next step in learning this piece? 


\section{Figure 12. Survey $B^{2}$}

Please fill out the following survey to the best of your ability, answering each prompt. You may be as concise or detailed as you deem necessary, but please provide any information you feel is relevant to the questions asked. You are not expected to fill the entire page, but if you need more space simply continue on the back of the page.

Did you warm up before this session? How much time did you devote to warming up today?

In simple terms, please describe your approach to learning this étude. Explain your thought processes, beginning with your first glance at the music. If you like, you may list your steps to learning this étude, and any specific techniques or methods you used during this session.

List any tools or practice aids you used today and explain why/how you used them.

In your opinion, what aspect(s) of your practice session today were MOST effective when learning this piece of music? Please describe at least one technique you used today that you felt was successful.

In your opinion, what aspect(s) of your practice session today were LEAST effective? Please describe at least one technique you used today that didn't work as well as you had hoped.

On a scale of $1-5$, how productive would you rate this practice session? Circle your answer.

$\begin{array}{llllllll}\text { Not productive at all } & 1 & 2 & 3 & 4 & 5 & \text { Extremely }\end{array}$ productive

If you had had more time to work on this étude, what would be your next step in learning this piece?

${ }^{2}$ The survey was abridged for the second session, with the necessary demographic and biographical information already having been gathered. 


\section{CURRICULUM VITAE}

NAME:

ADDRESS:

DOB:

EDUCATION AND TRAINING:
Jennifer Michelle Pope

821A East Muhammad Ali Blvd. Louisville, KY 40204

August 7, 1988

B.M.M.E.

University of Kentucky

2006-2010

Student Teacher

Lafayette High School

Spring 2010

M.M.E.

University of Louisville

2010-2012 